\title{
Effect of Humic Acid, Biofertilizers and Mineral Phosphate on Soil Microbial Activity and Productivity of Pea Plants under Toshka Conditions
}

\author{
El-Sayed M. A. Mahmoud ${ }^{1}$, El-Sayed M. Taha ${ }^{2}$
}

\begin{abstract}
Two field experiments were conducted during the winter season of $2015 / 2016 \& 2016 / 2017$, at Toshka Research Station - Desert Research Center. The aim of the study was to investigate the effect of humic acid (HA) at rates of 0,4 and $8 \mathrm{~kg} /$ fed. combined with phosphate dissolving bacteria(PDB) and mineral phosphate fertilizer at rates of $100,90,80$ and $70 \% \mathrm{P}_{2} \mathrm{O}_{5}$ of the recommended dose in commercial production on pea plants. Treatment with humic acid at $8 \mathrm{~kg}$ / fed. combined with inoculation of PDB and $100 \%$ of mineral phosphate fertilizer significantly increased the total microbial count, Bacillus megaterium count, $\mathrm{CO}_{2}$ evolution, organic carbon and phosphatase and dehydrogenase enzymes activities. The bio-fertilizer treatments (PDB) showed a clear superiority when added in combination with the phosphate fertilizer and humic acid compared to the results of using a mixture of humic acid and superphosphate only. Adding of humic acid and superphosphate with the presence of phosphate dissolving bacteria improved most of the vegetative growth characteristics of plants. Yield components had the highest positive response to humic acid combined with mineral fertilizer percentage with phosphate-dissolving bacteria. The highest concentration of $\mathbf{N}, \mathbf{P}$, and $\mathrm{K}$ were with the use of humic acid at $(8 \mathrm{~kg})$, phosphate-dissolving bacteria and $100 \%$ phosphate fertilization $\mathrm{P}_{2} \mathrm{O}_{5}$.
\end{abstract}

The study revealed that using $8 \mathrm{~kg} \mathrm{HA} / \mathrm{fed}$ in combination with PDB and high level of P2O5 as a fertilizer application to improve soil properties, vegetative growth, mineral content and yield of pea plants in new soils was recommended.

Key words: Microbial activity, Pea, Growth, yield components, Humic acid, Bio-fertilizers, Super phosphate ( $\left.\mathbf{P}_{2} \mathbf{O}_{5}\right)$, Toshka.

\section{INTRODUCTION}

The over increased world population required both horizontal and vertical agriculture extension to meet the increased food demands.Vasil (1998) and Leisinger (1999) reported that increasing food productivity by about $50 \%$ in the next twenty years is needed to meet the population pressure. Horizontal and vertical agriculture extension in desert areas faced with the problem of low soil fertility. Vikram and Hamzehzarghani (2008) stated that phosphorus is the second major macronutrients for plants because it has an important role in plant metabolism. Yagodin (1990) added that phosphorus has a great role in biosynthesis and translocation of carbohydrates, yield and fruits quality.

Most of soils contain large amounts of total phosphorus but only less than $10-15 \%$ of that $\mathrm{P}$ content enter the plant - animal cycle and the rest amount remained inert-due to its fixation (Kucey et al., 1989). Such inert phosphorus could become soluble and available to plants by the soil microorganisms (Palss, 1998; Hilda and Fraga, 1999). With this respect, Rodriguez and Fraga (1999) stated that strains from Pseudomonas, Bacillus and Rhizobium genera were among the most powerful phosphate solubilizes which, in turn, resulted in increases of $\mathrm{P}$ uptake and crop yield.

Using PDB inoculation was recommended to overcome the ever increasing cost of phosphorus mineral fertilizer and soil health maintenance (Babulkar et al., 2000) and avoiding its harmful effect on environment (Bogatyre, 2000). Rhizobacteria was also used to increase bioavailability of $\mathrm{P}$ and $\mathrm{K}$ in soils which resulted in increasing their uptake and plant growth (Lin et al. 2002; Sahin et al. 2004; Girgis, 2006 and Eweda et al. 2007). Han and Lee (2005) added that Phosphate solubilizing bacteria has used to convert insoluble phosphate compounds into a available soluble form for plant uptake. As a result, El-Gizawy et al (2009) found that adding $30 \mathrm{~kg} \mathrm{P}_{2} \mathrm{O}_{5}$ mineral fertilizer in combination with PDB markedly increased growth of bean plants as well as its yield, protein content and mineral uptake. Abdel-Kader and Selah (2017) found, that growth of Roselle plants and its yield was significantly increased due to co-inoculation of PDB (Bacillus megaterium var. phosphaticum) and KSB (Bacillus mucilaginosus) combined with rock phosphate and feldspar.

Humic acid (HA) application is a wide spread compound used in agriculture development. It improves physical, chemical, fertility and biological properties of soils (Keeling et al., 2003; Nardi et al., 2004; Mikkelsen, 2005; Sarir et al., 2005 and Mart, 2007). Such positive effects of humic acid on soil properties reflected on positive effects on plants (Ashraf et al., 2005 and Susilawati et al., 2009) through improving mineral availability (Mauromicale et al., 2011) and

DOI: 10.21608/ASEJAIQJSAE.2020.129374

${ }^{1}$ Soil Fertility and Microbiology Department, Desert Research Center, El-Mataria, Cairo, Egypt

mahalyeg@yahoo.com

${ }^{2}$ Plant Production Dept., Desert Research Center, Cairo, Egypt

Received November 05, 2020, Accepted, December 12, 2020 
enhancing nutrients uptake (Mackowiak et al., 2001 and Mauromicale et al., 2011). Likewise, humic acid application increased yield of vegetables such as tomatoes, potatoes, onions, pepper, Peas and other leafy vegetables (Erik et al., 2000; Albayrak, 2005; Vetayasuporn, 2006; Mohamed et al., 2009 and Khan et al., 2013).

Sarwar et al.(2014) found that rhizobacteria (PGPR) inoculation combined with humic acid (HA) and $\mathrm{P}_{2} \mathrm{O}_{5}$ recorded the highest grain yield of mung bean and gave the highest concentration of $\mathrm{P}$ and $\mathrm{N}$ in mung bean shoot as well as improved P use efficiency (PUE) and enhanced $\mathrm{P}$ availability through chelating and reduce soil $\mathrm{P}$ fixation.

Keeping the declining soil fertility, ever increasing mineral fertilizer costs and continuous increasing demand for more food, the current study aimed to investigate the effect of humic acid, biofertilizers and phosphorus application as well as their interactions on microbial activity, mineral content and pea growth and yield grown at Toshka region.

\section{MATERIALS AND METHODS}

Two experiments were carried out in 2016 / 2017 and 2017 /2018 at Toshka Experimental Station, South Egypt. The aim of the study was to investigate the effect of humic acid, biofertilizers and phosphorus application on microbial activity, mineral contents and growth and yield of pea plants.

The composite soil samples were collected before planting at depth of 0-30 cm; air dried and sieved (2 $\mathrm{mm})$.
Some physical and chemical properties of the experimental farm soil and irrigation water were determined according to Klute (1986), Jackson (1973) and shown in Tables (A and B.).

\section{Treatments:}

\section{1)Humic acid treatments:}

Humic acid was applied as soil addition at rates of zero (control), 4 and $8 \mathrm{~kg} / \mathrm{fed}$. Twice after germination and at flowering. The source of humic acid is potassium humate, which contains $60 \%$ humic acids and $8 \% \mathrm{~K}_{2} \mathrm{O}$.

\section{2)Biofertilizer treatments:}

Bacillus megaterium as bacterial suspensions $\left(10^{8} \mathrm{cfu} / \mathrm{ml}\right)$ with Carboxy methyl cellulose $0.5 \%$ as an adhesive agent was applied to grains at planting time and the inoculation was repeated after 30 days of germination. Control treatment without bacterial inoculation was also designed. Isolates has been produced in soil microbiology laboratory, Desert Research Center (DRC).

\section{3)Phosphorus treatments:}

Superphosphate $(15.5 \%)$ was incorporated into the soil two weeks before planting at the following rates:

1)100 \% of the recommended dose $(200 \mathrm{~kg}$ superphosphate / fed)

2) $90 \%$ of the recommended dose $(180 \mathrm{~kg}$ superphosphate / fed)

$3) 80 \%$ of the recommended dose $(160 \mathrm{~kg}$ superphosphate / fed)

$4) 70 \%$ of the recommended dose $(140 \mathrm{~kg}$ superphosphate / fed)

Table A. Some physical and chemical properties of soil in studied area

\begin{tabular}{|c|c|c|c|c|c|c|c|c|c|c|c|c|c|}
\hline \multicolumn{4}{|c|}{ Particle size distribution } & \multirow{3}{*}{$\begin{array}{c}\text { Organic } \\
\text { matter } \\
(\%)\end{array}$} & \multicolumn{9}{|c|}{ Chemical properties } \\
\hline \multirow{2}{*}{$\begin{array}{c}\text { Sand } \\
(\%)\end{array}$} & \multirow{2}{*}{$\begin{array}{l}\text { Silt } \\
(\%)\end{array}$} & \multirow{2}{*}{$\begin{array}{c}\text { Clay } \\
(\%)\end{array}$} & \multirow{2}{*}{ Texture } & & \multirow{2}{*}{$\mathbf{p H}$} & \multirow{2}{*}{$\begin{array}{c}\text { E.C. } \\
\text { dS.m. }\end{array}$} & \multicolumn{3}{|c|}{ Soluble anions (mg/L.) } & \multicolumn{4}{|c|}{ Soluble cations (mg/L.) } \\
\hline & & & & & & & $\mathrm{HCO}_{3}=$ & $\mathrm{Cl}^{-}$ & $\mathrm{SO}_{4}=$ & $\mathrm{Ca}^{++}$ & $\mathbf{M g}^{++}$ & $\mathrm{Na}^{+}$ & $\mathbf{K}^{+}$ \\
\hline 50.88 & 21.84 & 27.28 & SCL & 0.67 & 8.62 & 3.98 & 7.61 & 11.71 & 20.48 & 8.21 & 3.49 & 26.99 & 1.11 \\
\hline
\end{tabular}

$\mathrm{SCL}=$ Sandy clay loam.

Table B. Analysis of the irrigation water:

\begin{tabular}{|c|c|c|c|c|c|c|c|c|c|c|c|c|c|}
\hline \multirow{2}{*}{$\begin{array}{l}\text { well } \\
\text { No. }\end{array}$} & \multirow{2}{*}{ pH } & \multirow{2}{*}{$\begin{array}{c}\mathbf{E C} \\
(\mu \mathrm{S} / \mathrm{cm})\end{array}$} & \multirow{2}{*}{ TDS mg/l } & & \multicolumn{5}{|c|}{ Soluble cations } & \multicolumn{4}{|c|}{ Soluble anions } \\
\hline & & & & & $\mathrm{Ca}^{++}$ & $\mathrm{Mg}^{++}$ & $\mathbf{N a}^{+}$ & $\mathbf{K}^{+}$ & & $\mathrm{CO}_{3}^{--}$ & $\mathrm{HCO}_{3}{ }^{-}$ & $\mathrm{SO}_{4}^{--}$ & $\mathrm{Cl}^{-}$ \\
\hline \multirow{6}{*}{85} & & & & ppm & 81.32 & 11.29 & 50.00 & 2.00 & & 3.00 & 111.15 & 151.25 & 87.98 \\
\hline & 6.9 & 768 & 447.25 & ppm & 4.06 & 0.93 & 2.18 & 0.05 & & 0.10 & 1.82 & 3.15 & 2.48 \\
\hline & & & & $\%$ & 56.26 & 12.87 & 30.16 & 0.71 & & 1.32 & 24.12 & 41.70 & 32.85 \\
\hline & \multicolumn{13}{|c|}{ Trace elements (mg/L) } \\
\hline & Ag & Al & $\mathbf{C d}$ & Co & $\mathrm{Cr}$ & $\mathbf{F e}$ & Mn & Mo & $\mathbf{N i}$ & $\mathbf{P b}$ & $\mathbf{S i}$ & $\mathbf{S r}$ & $\mathbf{Z n}$ \\
\hline & n.d. & n.d. n.d. & 0.05 n.d. & n.d. & $0.15 \quad 0.02$ & 0.25 & 0.002 & n.d. & 0.014 & $4 \quad 0.003$ & 4 & 0.35 n.d. & 0.008 \\
\hline
\end{tabular}


Organic manure (EL-Nile Compost) was provided from ECARU (Egyptian Company for Agriculture Residues Utilization) Dokki, Giza, Egypt, and mixed into the soil surface two weeks before planting; its analysis was: $\mathrm{pH} 6.81$, EC $2.91 \mathrm{dSm}^{-1}$, total $\mathrm{N} 1.21 \%$, total $\mathrm{P} 0.25 \%$, total $\mathrm{K} 0.62 \%$ and $\mathrm{C} / \mathrm{N}$ 17.31. In addition, Rhizobium leguminosarum was added two times (during planting and after germination), which were isolated by microbiology laboratory at the Desert Research Center (DRC). 200kg ammonia sulfate/fed. and $100 \mathrm{~kg}$ potassium sulphate/fed were divided into two doses and added after germination and flowering.

Soil samples were collected from the soil at depth of 0-30 $\mathrm{cm}$ at 90 days from pea sowing to estimate density of total microbial and PDB which were quantified on yeast extract agar medium (Allen, 1959) and modified by Bunt and Rovira medium (Abd El-Hafez, 1966) using the dilution frequency method. $\mathrm{CO}_{2}$ evolution ( $\mu \mathrm{g} / \mathrm{g}$ dry soil/ hr.), dehydrogenase activity ( $\mu \mathrm{g}$ TPF g- ${ }^{1}$. dry soil 24h.) and phosphatase enzyme (PNP g/soil/h) in the rhizosphere were determined according to Pramer and Schmidt (1994), Thalmann (1967) and Tabatabai and Brimner, (1969), respectively. Organic carbon content was determined by Walkley and Black's wet oxidation method (1934) and $\mathrm{CO}_{2}$ evolution $(\mu \mathrm{g} / \mathrm{g}$ dry soil/ hr.) in the rhizosphere were determined according to Pramer and Schmidt (1994). Total nitrogen percentage was determined by using the modified microkjeldahl method as described by Peach and Tracey (1956). Available phosphorous was extracted using 0.5 $\mathrm{M} \mathrm{NaHCO}_{3}$ at pH 8.5 according to Olsen et al. (1982) and measured colorimetrically using the chlorostannus phosphomolybdic-sulfuric acid method as described by Jackson (1973). Electrical conductivity (EC) and soil $\mathrm{pH}$ was determined in a 1:2.5 soil to water extract using conductivity meter and Beckman $\mathrm{pH}$ meter, respectively according to Jackson (1973) and McLean (1982).

Plant height $(\mathrm{cm})$, number of branches /plant, fresh and dry weights (gm) /plant of shoots and number of leaves /plant were recorded before harvest (after 95 days from sowing). Whereas, total chlorophyll (SPAD unit) was determined according to A.O.A.C. (1990). Nitrogen content of pea seeds (\%) were determined using Micro-Kjeldhl method according to Peach and Tracey (1956). Phosphorus content of pea seeds (\%) were estimated using Spectrocolormeter and potassium content of pea seeds by using Flame photometer (Jackson, 1973).

At the harvest, plants of one row from each experimental plot were harvested to estimate yield parameters such as number of dry pods /plant, length of pods $(\mathrm{cm})$, diameter of pods $(\mathrm{mm})$, average seed number /dry pod, average weight of seeds (g)/pod and weight of seed yield.

\section{Experimental design and statistical analysis:}

Split plot design was used with three replicates. Main plots were assigned for humic acid and sub plots were used for bio-fertilization; where phosphorus treatments were distributed in the sub sub plots. Obtained data were subjected to statistical analysis according to (Snedecor and Cochran, 1989).

\section{RESULTS AND DISCUSSION}

\section{Microbial activity and Soil estimates:}

Data concerned with the effect of humic acid, biofertilizers and phosphorus application on microbial activity expressed as total microbial counts, PDB density, $\mathrm{CO}_{2}$ evolution, organic carbon, dehydrogenase activity (DHA) and phosphatase enzyme. Obtained data were presented in Tables (1, 2 and 3). As for soil estimates, Obtained data concerned with total nitrogen, available phosphorus, $\mathrm{C} / \mathrm{N}$ ratio and $\mathrm{C} / \mathrm{P}$ ratio in the soil cultivated with pea plants at Toshka region were presented in Tables (4- 5). Results indicated significant positive effect for either humic acid, biofertilizers and phosphorus application on the investigated characters, the highest values were obtained with $8 \mathrm{~kg}$ humic acid, PDB inoculation or $100 \%$ of phosphorus recommended dose (200 kg superphosphate / fed.). These results are in accordance with those reported by Pandya and Saraf (2010), Amal M. Omer (2010) who mentioned that biofertilizers application can increase the availability of nutrients by their biological activity, which in turn, improve soil fertility by increasing the number of such microorganisms and accelerate certain microbial processes. In addition, Yosefi et al. (2011) reported that biofertilizers improved soil fertility. It solubilized insoluble soil phosphates and increased plant growth substances in the soil.

With this respect, it is of interest to mention that multiple regression of Bacillus megaterium count (count $\times 10^{4} \mathrm{CFU}$ ) on total microbial count and total microbial count without Bacillus megaterium was presented in equation (1 and 2). Regression coefficients indicated that Bacillus megaterium count was increased in the first season an average of 0.00062 unit for each unit of total microbial count but only 0.00010 for each unit of total microbial count without Bacillus megaterium. The corresponding values in the second were 0.01102 and 0.0002 . This indicated that total microbial was more effective than total microbial count without Bacillus megaterium; in the same time indicated that total microbial count other than Bacillus megaterium increased Bacillus megaterium count which could lead to conclude that there were mutual cooperation effect for some other bacteria on Bacillus megaterium. Such conclusion was true in both investigated seasons. 
$\mathrm{Y}^{\wedge}=17.4+0.00062 * \mathrm{X}_{1}+0.00010 * \mathrm{X}_{2}$ Equation (1) for the first season

$\mathrm{Y}^{\wedge}=45.9+0.01102 * \mathrm{X}_{1}+0.00023 * \mathrm{X}_{2}$ Equation (1) for the second season

Where Y stand for the dependent variable Bacillus megaterium count (count $\times 10^{4} \mathrm{CFU}$ ), the independent variables $\mathrm{X}_{1}$ stand for total microbial count (count $\times 10^{4}$ $\mathrm{CFU}$ ) and $\mathrm{x}_{2}$ stand for total microbial count without Bacillus megaterium (count $\times 10^{4} \mathrm{CFU}$ )

It is, also, of great interest to know the relation between Bacillus megaterium density (count $\times 10^{4} \mathrm{CFU}$ ) and the available phosphorus in the soil (\%). Linear correlation indicated that there was highly significant positive correlation between the available phosphorus in the soil and Bacillus megaterium density. Correlation coefficients (r) were 0.945 and 0.946 in the first and second seasons, respectively. Linear regression of the available phosphorus in the soil on the independent variable showed that regression coefficients were 7.31 and 9.9 in the first and second seasons, respectively. This means that soil available phosphorus would increase by 7.31 and $9.9 \%$ in the first and second seasons, respectively, for each unit increase of Bacillus megaterium.

As for the interactions, the highest values were obtained generally with application of either $8 \mathrm{~kg}$ humic acid / fed combined with PDB inoculation or $8 \mathrm{~kg}$ humic acid / fed combined with $100 \%$ of phosphorus recommended dose. The beneficial effect of humic acid on microbial activity may be due to its activation through its positive effects on soil and plant characteristics (Zhang and Ervin, 2004), its various functional groups which, in turn, stimulate enzyme activity, membrane permeability, photosynthesis and respiration (Muscolo et al., 2007 and Nardi et al., 2002), its useful effects in minimizing the amount of mineral fertilization (Eman Abdel-Monem et al., 2008). In addition, biofertilizer inoculation plays an important role in exchanges of $\mathrm{CO}_{2}$ between land biosphere and atmosphere through soil microbial activity and $\mathrm{CO}_{2}$ production (Luo and Zhou, 2006) as well as biofertilizer inoculation led to higher dehydrogenase activity than those in un-inoculated treatments (Amal et al. 2014). In this respect, Al-Haddad et al. (2014) showed that the highest significant increase in percentages of enzyme activity (dehydrogenase) was recorded in the Eucalyptus camaldulensis inoculated with a mixed microbial treatment of (Azotobacter chroococcum, Bacillus circulans and Arbuscular mycorrhizal fungi AMF) rather than those of individual and dual treatments in the two investigated seasons.

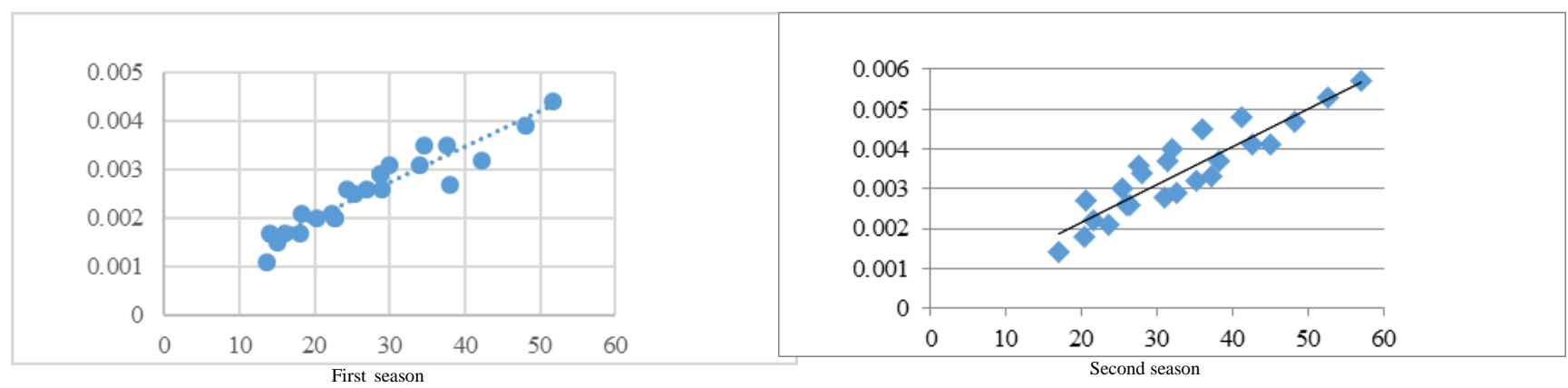

Fig. 1. Regression of available $P(Y, \%)$ on Bacillus megaterium $\left(X\right.$, count $\left.\times 10^{4} \mathrm{CFU}\right)$

\footnotetext{
$\mathrm{Y}^{\wedge}=0.000542+7.31 \mathrm{E}-05 \mathrm{X}, \mathrm{r}=0.945$ in the 1_st season.

$\mathrm{Y}^{\wedge}=0.000693+9.9 \mathrm{X}, \mathrm{r}=0.946$ in the 2_nd season.
} 
Table 1. Influence of humic acid, biofertilizers and phosphorus applications on total microbial counts (Counts $\mathrm{x} 10^{6}$ CUF $\mathrm{g}$ dry soil) and Bacillus megaterium count (count $\times 10^{4}$ CUF) during $2016 / 2017$ seasons

\begin{tabular}{|c|c|c|c|c|c|c|c|c|c|c|c|c|c|c|c|c|c|}
\hline \multirow{4}{*}{$\begin{array}{c}\text { Bacterial } \\
\text { Inoculation } \\
\mathbf{S}\end{array}$} & \multirow{4}{*}{$\begin{array}{c}\text { Phosphorus } \\
\%\end{array}$} & \multicolumn{8}{|c|}{ Total microbial count $\left(\right.$ count $\left.\times 10^{6} \mathrm{CUF}\right)$} & \multicolumn{8}{|c|}{ Bacillus megaterium count (count $\left.\times 10^{4} \mathrm{CUF}\right)$} \\
\hline & & \multicolumn{4}{|c|}{ First Season } & \multicolumn{4}{|c|}{ Second Season } & \multicolumn{4}{|c|}{ First season } & \multicolumn{4}{|c|}{ Second Season } \\
\hline & & \multicolumn{8}{|c|}{ Humic Acid } & \multicolumn{8}{|c|}{ Humic Acid } \\
\hline & & Without & $\begin{array}{l}4 \mathrm{Kg} \\
/ \text { fed. }\end{array}$ & $\begin{array}{l}8 \mathrm{Kg} \\
\text { /fed. }\end{array}$ & Mean & Without & $\begin{array}{c}4 \mathrm{Kg} \\
\text { /fed. }\end{array}$ & $\begin{array}{l}8 \mathrm{Kg} \\
/ \text { fed. }\end{array}$ & Mean & Without & $\begin{array}{l}4 \mathrm{Kg} \\
/ \text { fed. }\end{array}$ & $\begin{array}{l}8 \mathrm{Kg} \\
\text { /fed. }\end{array}$ & Mean & Without & $\begin{array}{c}4 \mathrm{Kg} \\
\text { /fed. }\end{array}$ & $\begin{array}{c}8 \mathrm{Kg} \\
\text { /fed. }\end{array}$ & Mean \\
\hline \multirow{4}{*}{ Without } & 100 & 31.33 & 35.33 & 39.33 & 35.33 & 37.33 & 41.00 & 48.67 & 42.33 & 22.33 & 28.67 & 34.67 & 28.56 & 26.33 & 37.33 & 42.67 & 35.44 \\
\hline & 90 & 28.67 & 32.67 & 35.67 & 32.33 & 35.00 & 38.33 & 46.00 & 39.78 & 18.00 & 25.33 & 30.00 & 24.44 & 23.67 & 32.67 & 38.33 & 31.56 \\
\hline & 80 & 27.00 & 31.33 & 34.67 & 31.00 & 33.33 & 36.67 & 42.67 & 37.56 & 15.00 & 20.33 & 27.00 & 20.78 & 20.33 & 26.00 & 35.33 & 27.22 \\
\hline & 70 & 21.00 & 30.67 & 33.00 & 28.22 & 31.33 & 34.00 & 39.00 & 34.78 & 13.67 & 16.00 & 22.67 & 17.44 & 17.00 & 21.67 & 31.00 & 23.22 \\
\hline \multicolumn{2}{|c|}{ Mean } & 27.00 & 32.50 & 35.67 & 31.72 & 34.25 & 37.50 & 44.08 & 38.61 & 17.25 & 22.58 & 28.58 & 22.81 & 21.83 & 29.42 & 36.83 & 29.36 \\
\hline \multirow{4}{*}{ PDB } & 100 & 38.33 & 47.00 & 84.00 & 56.44 & 42.67 & 51.33 & 91.00 & 61.67 & 28.67 & 37.67 & 51.67 & 39.33 & 31.33 & 41.33 & 57.00 & 43.22 \\
\hline & 90 & 32.67 & 42.67 & 78.33 & 51.22 & 38.33 & 47.67 & 86.33 & 57.44 & 24.33 & 34.00 & 48.00 & 35.44 & 28.00 & 36.00 & 52.67 & 38.89 \\
\hline & 80 & 29.67 & 38.00 & 68.67 & 45.44 & 36.67 & 43.33 & 77.00 & 52.33 & 18.33 & 29.00 & 42.33 & 29.89 & 25.33 & 32.00 & 48.33 & 35.22 \\
\hline & 70 & 25.33 & 33.00 & 62.67 & 40.33 & 34.00 & 37.00 & 66.00 & 45.67 & 14.00 & 22.67 & 38.00 & 24.89 & 20.67 & 27.67 & 45.00 & 31.11 \\
\hline \multicolumn{2}{|c|}{ Mean } & 31.50 & 40.17 & 73.42 & 48.36 & 37.92 & 44.83 & 80.08 & 54.28 & 21.33 & 30.83 & 45.00 & 32.39 & 26.33 & 34.25 & 50.75 & 37.11 \\
\hline \multirow{4}{*}{$\mathrm{P} \times \mathrm{HU}$} & 100 & 34.83 & 41.17 & 61.67 & 45.89 & 40.00 & 46.17 & 69.83 & 52.00 & 25.50 & 33.17 & 43.17 & 33.94 & 28.83 & 39.33 & 49.83 & 39.33 \\
\hline & 90 & 30.67 & 37.67 & 57.00 & 41.78 & 36.67 & 43.00 & 66.17 & 48.61 & 21.17 & 29.67 & 39.00 & 29.94 & 25.83 & 34.33 & 45.50 & 35.22 \\
\hline & 80 & 28.33 & 34.67 & 51.67 & 38.22 & 35.00 & 40.00 & 59.83 & 44.94 & 16.67 & 24.67 & 34.67 & 25.33 & 22.83 & 29.00 & 41.83 & 31.22 \\
\hline & 70 & 23.17 & 31.83 & 47.83 & 34.28 & 32.67 & 35.50 & 52.50 & 40.22 & 13.83 & 19.33 & 30.33 & 21.17 & 18.83 & 24.67 & 38.00 & 27.17 \\
\hline \multicolumn{2}{|c|}{ Mean } & 29.25 & 36.33 & 54.54 & & 36.08 & 41.17 & 62.08 & & 19.29 & 26.71 & 36.79 & & 24.08 & 31.83 & 43.79 & \\
\hline \multicolumn{18}{|l|}{ LSD 5\% } \\
\hline & & & & 3.037 & & & & 2.883 & & & & 0.914 & & & & 0.921 \\
\hline \multicolumn{2}{|l|}{ Biofertilizer } & & & & 3.595 & & & & 1.997 & & & & 1.391 & & & & 0.821 \\
\hline \multicolumn{2}{|l|}{ Phosphrus } & & & & 1.164 & & & & 2.918 & & & & 0.734 & & & & 0.849 \\
\hline \multicolumn{2}{|l|}{ Humic*Bio } & & & & 6.226 & & & & 3.459 & & & & 2.410 & & & & 1.423 \\
\hline \multicolumn{2}{|c|}{ Humic*Phosphorus } & & & & 2.016 & & & & 5.054 & & & & 1.272 & & & & 1.470 \\
\hline \multicolumn{2}{|c|}{ Bio*Phosphorus } & & & & 1.366 & & & & 3.423 & & & & 0.861 & & & & NS \\
\hline \multicolumn{2}{|c|}{ Humic*Bio*Phosphorus } & & & & 2.366 & & & & $\mathrm{NS}$ & & & & 1.492 & & & & NS \\
\hline
\end{tabular}

*- Initial total bacterial count was $50 \times 10^{3}(\mathrm{CFU} / \mathrm{g}$ dry soil)

*- Initial total Bacillus count was $45 \times 10^{2}$ (CFU/g dry soil).

*- $\mathrm{P} \times \mathrm{HU}=$ Interaction of Phosphorus treatment with humic acid treatments. 
El-Sayed, M. A. Mahmoud., El-Sayed M. Taha. Effect of Humic Acid, Biofertilizers and Mineral Phosphate on Soil .......... 494

Table 2. Influence of Humic acid, biofertilizers and Phosphorus applications on $\mathrm{CO}_{2}$ evolution (mg $\mathrm{CO}_{2} / 100 \mathrm{~g}$ dry soil $/ 24 \mathrm{hr}$.) and $\mathrm{Organic}$ carbon $\%$ during 2016/2017 seasons

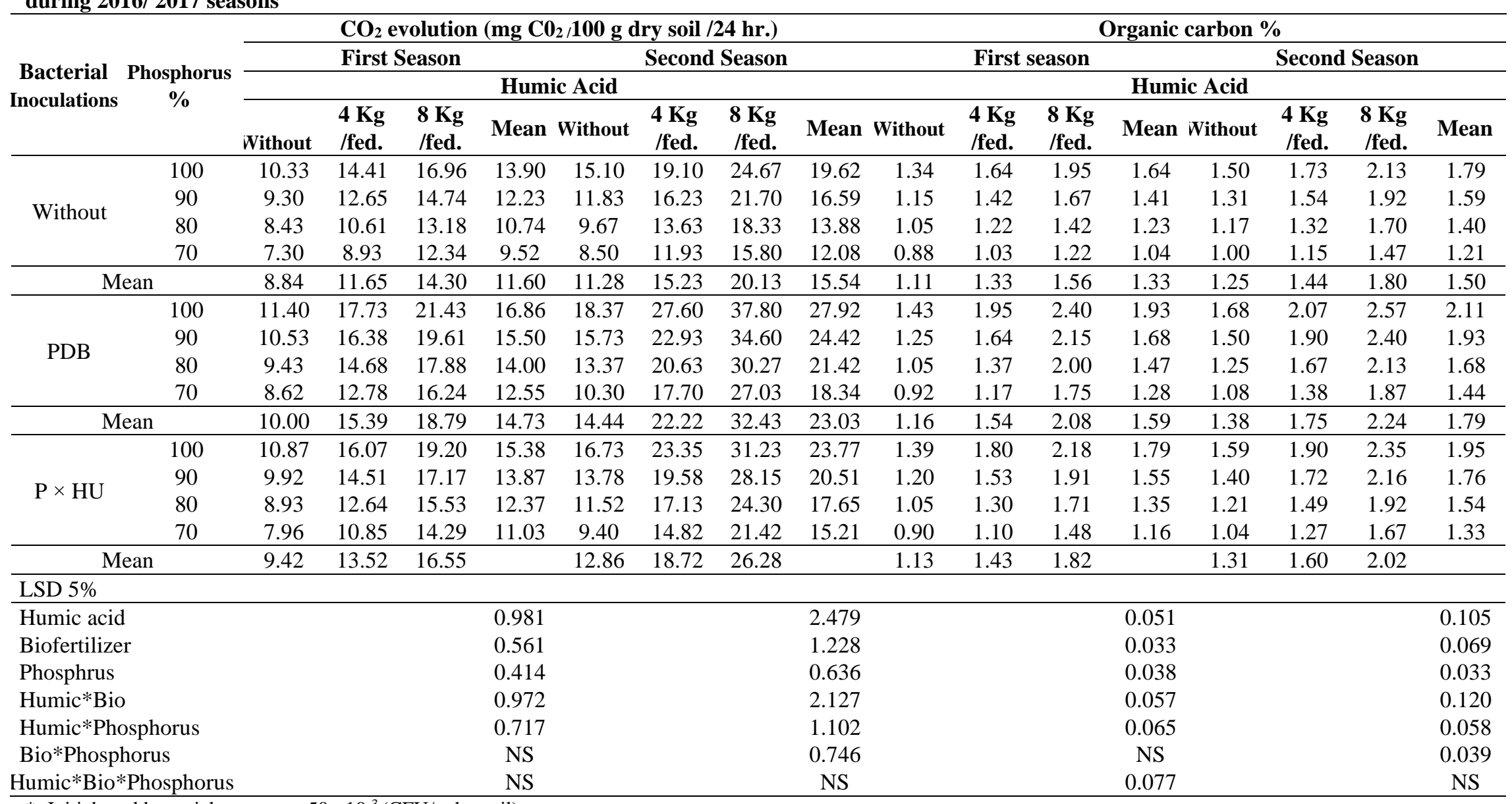

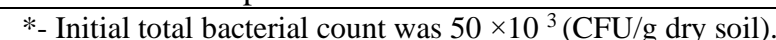

*- Initial total Bacillus count was $45 \times 10^{2}$ (CFU/g dry soil).

$*_{-} \mathrm{P} \times \mathrm{HU}=$ Interaction of Phosphorus treatment with humic acid treatments. 
Table 3. Influence of Humic acid, biofertilizers and Phosphorus applications on phosphatase enzyme (PNP g/soil/h) and dehydrogenase activity (DHA) ( $\mu$ g TPF g- ${ }^{-1}$. dry soil 24hr.) during 2016/ 2017 seasons

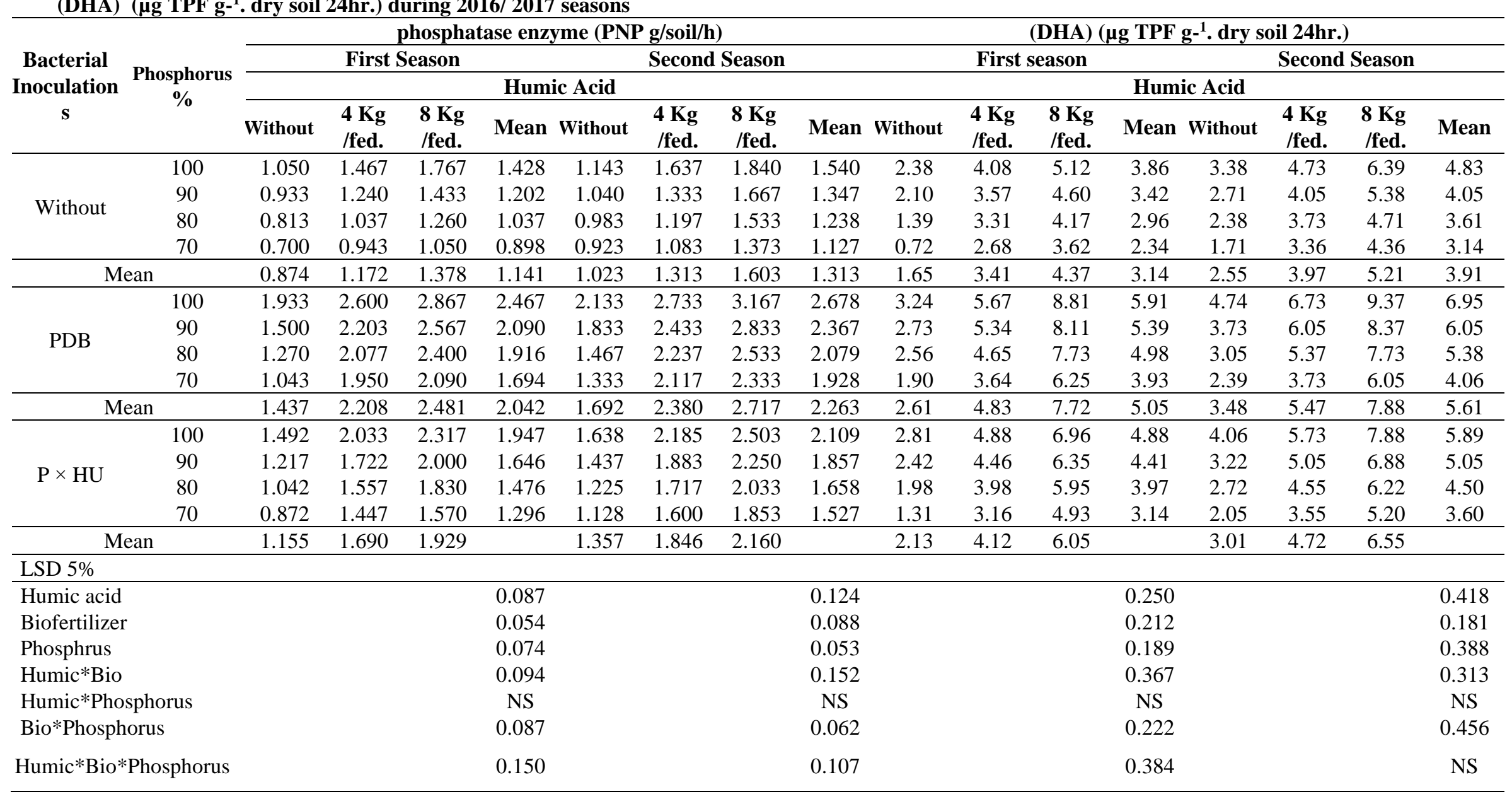

\footnotetext{
*- Initial phosphatase enzyme 0.65 (PNP g/soil/h)

*- Initial Dehydrogenase activity 2.01 ( $\mu \mathrm{g}$ TPF g-1 dry soil 24h.)

*- para-nitrophenol (PNP)

$*_{-} \mathrm{P} \times \mathrm{HU}=$ Interaction of Phosphorus treatment with humic acid treatments.
} 
Table 4. Influence of Humic acid, biofertilizers and Phosphorus applications on total nitrogen in soil \% and C/N ratio during $2016 / 2017$ seasons

\begin{tabular}{|c|c|c|c|c|c|c|c|c|c|c|c|c|c|c|c|c|c|}
\hline \multirow{4}{*}{$\begin{array}{c}\text { Bacterial } \\
\text { Inoculations }\end{array}$} & \multirow{4}{*}{$\begin{array}{c}\text { Phosphorus } \\
\%\end{array}$} & \multicolumn{8}{|c|}{ Total nitrogen in soil \% } & \multicolumn{8}{|c|}{$\mathrm{C} / \mathrm{N}$ ratio } \\
\hline & & \multicolumn{4}{|c|}{ First Season } & \multirow{2}{*}{\multicolumn{4}{|c|}{$\begin{array}{ll} & \text { Second Season } \\
\text { Acid } & \end{array}$}} & \multicolumn{4}{|c|}{ First season } & \multicolumn{4}{|c|}{ Second Season } \\
\hline & & \multicolumn{4}{|c|}{ Humic Acid } & & & & & \multicolumn{8}{|c|}{ Humic Acid } \\
\hline & & Without & $\begin{array}{l}4 \mathrm{Kg} \\
\text { /fed. }\end{array}$ & $\begin{array}{l}8 \mathrm{Kg} \\
\text { /fed. }\end{array}$ & Mean & Without & $\begin{array}{l}4 \mathrm{Kg} \\
\text { /fed. }\end{array}$ & $\begin{array}{l}8 \mathrm{Kg} \\
\text { /fed. }\end{array}$ & Mean & Without & $\begin{array}{l}4 \mathrm{Kg} \\
\text { /fed. }\end{array}$ & $\begin{array}{l}8 \mathrm{Kg} \\
\text { /fed. }\end{array}$ & Mean & Without & $\begin{array}{l}4 \mathrm{Kg} \\
\text { /fed. }\end{array}$ & $\begin{array}{l}8 \mathrm{Kg} \\
\text { /fed. }\end{array}$ & Mean \\
\hline \multirow{4}{*}{ Without } & 100 & 0.20 & 0.31 & 0.36 & 0.29 & 0.27 & 0.39 & 0.43 & 0.36 & 6.70 & 5.29 & 5.46 & 5.82 & 5.49 & 4.48 & 5.00 & 4.99 \\
\hline & 90 & 0.17 & 0.27 & 0.34 & 0.26 & 0.23 & 0.35 & 0.40 & 0.33 & 6.75 & 5.27 & 4.96 & 5.66 & 5.76 & 4.37 & 4.83 & 4.99 \\
\hline & 80 & 0.13 & 0.22 & 0.28 & 0.21 & 0.19 & 0.30 & 0.36 & 0.29 & 8.08 & 5.48 & 5.01 & 6.19 & 6.08 & 4.35 & 4.72 & 5.05 \\
\hline & 70 & 0.11 & 0.15 & 0.24 & 0.17 & 0.16 & 0.28 & 0.33 & 0.26 & 8.03 & 7.03 & 5.01 & 6.69 & 6.37 & 4.15 & 4.41 & 4.98 \\
\hline \multicolumn{2}{|c|}{ Mean } & 0.15 & 0.24 & 0.31 & 0.23 & 0.21 & 0.33 & 0.38 & 0.31 & 7.22 & 5.59 & 5.13 & 5.98 & 5.85 & 4.35 & 4.76 & 4.99 \\
\hline \multirow{4}{*}{ PDB } & 100 & 0.29 & 0.40 & 0.67 & 0.45 & 0.34 & 0.47 & 0.78 & 0.53 & 4.99 & 4.84 & 3.57 & 4.47 & 4.95 & 4.43 & 3.28 & 4.22 \\
\hline & 90 & 0.25 & 0.34 & 0.60 & 0.40 & 0.31 & 0.41 & 0.71 & 0.48 & 5.00 & 4.88 & 3.57 & 4.48 & 4.89 & 4.63 & 3.38 & 4.30 \\
\hline & 80 & 0.20 & 0.28 & 0.55 & 0.34 & 0.27 & 0.38 & 0.66 & 0.43 & 5.25 & 4.90 & 3.66 & 4.60 & 4.68 & 4.39 & 3.25 & 4.11 \\
\hline & 70 & 0.17 & 0.25 & 0.54 & 0.32 & 0.23 & 0.33 & 0.58 & 0.38 & 5.49 & 4.69 & 3.26 & 4.48 & 4.71 & 4.15 & 3.22 & 4.03 \\
\hline \multicolumn{2}{|c|}{ Mean } & 0.23 & 0.32 & 0.59 & 0.38 & 0.29 & 0.40 & 0.68 & 0.46 & 5.15 & 4.83 & 3.52 & 4.50 & 4.82 & 4.41 & 3.28 & 4.17 \\
\hline \multirow{4}{*}{$\mathrm{P} \times \mathrm{HU}$} & 100 & 0.24 & 0.36 & 0.52 & 0.37 & 0.31 & 0.43 & 0.61 & 0.45 & 5.71 & 5.03 & 4.22 & 4.99 & 5.19 & 4.45 & 3.88 & 4.51 \\
\hline & 90 & 0.21 & 0.30 & 0.47 & 0.33 & 0.27 & 0.38 & 0.55 & 0.40 & 5.70 & 5.06 & 4.07 & 4.94 & 5.25 & 4.51 & 3.90 & 4.55 \\
\hline & 80 & 0.17 & 0.25 & 0.42 & 0.28 & 0.23 & 0.34 & 0.51 & 0.36 & 6.36 & 5.15 & 4.12 & 5.21 & 5.27 & 4.36 & 3.77 & 4.47 \\
\hline & 70 & 0.14 & 0.20 & 0.39 & 0.24 & 0.19 & 0.31 & 0.46 & 0.32 & 6.52 & 5.57 & 3.80 & 5.30 & 5.40 & 4.15 & 3.65 & 4.40 \\
\hline \multicolumn{2}{|c|}{ Mean } & 0.19 & 0.28 & 0.45 & & 0.25 & 0.36 & 0.53 & & 6.00 & 5.15 & 4.06 & & 5.27 & 4.38 & 3.81 & \\
\hline \multicolumn{18}{|l|}{ LSD 5\% } \\
\hline \multicolumn{2}{|l|}{ Humic acid } & & & & 0.017 & & & & 0.015 & & & & 0.849 & & & & 0.395 \\
\hline \multicolumn{2}{|l|}{ Biofertilizer } & & & & 0.013 & & & & 0.008 & & & & 0.571 & & & & 0.157 \\
\hline \multicolumn{2}{|l|}{ Phosphrus } & & & & 0.013 & & & & 0.009 & & & & 0.464 & & & & 0.102 \\
\hline \multicolumn{2}{|l|}{ Humic*Bio } & & & & 0.023 & & & & 0.014 & & & & 0.989 & & & & 0.271 \\
\hline \multicolumn{2}{|c|}{ Humic*Phosphorus } & & & & 0.023 & & & & 0.016 & & & & 0.804 & & & & 0.176 \\
\hline \multicolumn{2}{|c|}{ Bio*Phosphorus } & & & & 0.015 & & & & 0.011 & & & & 0.545 & & & & 0.119 \\
\hline \multicolumn{2}{|c|}{ Humic*Bio*Phosphorus } & & & & NS & & & & 0.019 & & & & 0.944 & & & & 0.206 \\
\hline
\end{tabular}

\footnotetext{
*- Initial total nitrogen in soil $0.09 \%$

*- Initial C/N ratio in soil $9.33 \%$

$*_{-} \mathrm{P} \times \mathrm{HU}=$ Interaction of Phosphorus treatment with humic acid treatments.

$*_{-} \mathrm{C} / \mathrm{N}$ ratio = Organic Carbon \% / Total nitrogen \%
} 
Table 5. Influence of Humic acid, biofertilizers and Phosphorus applications on available phosphorus \% and C/P ratio during 2016/ 2017 seasons

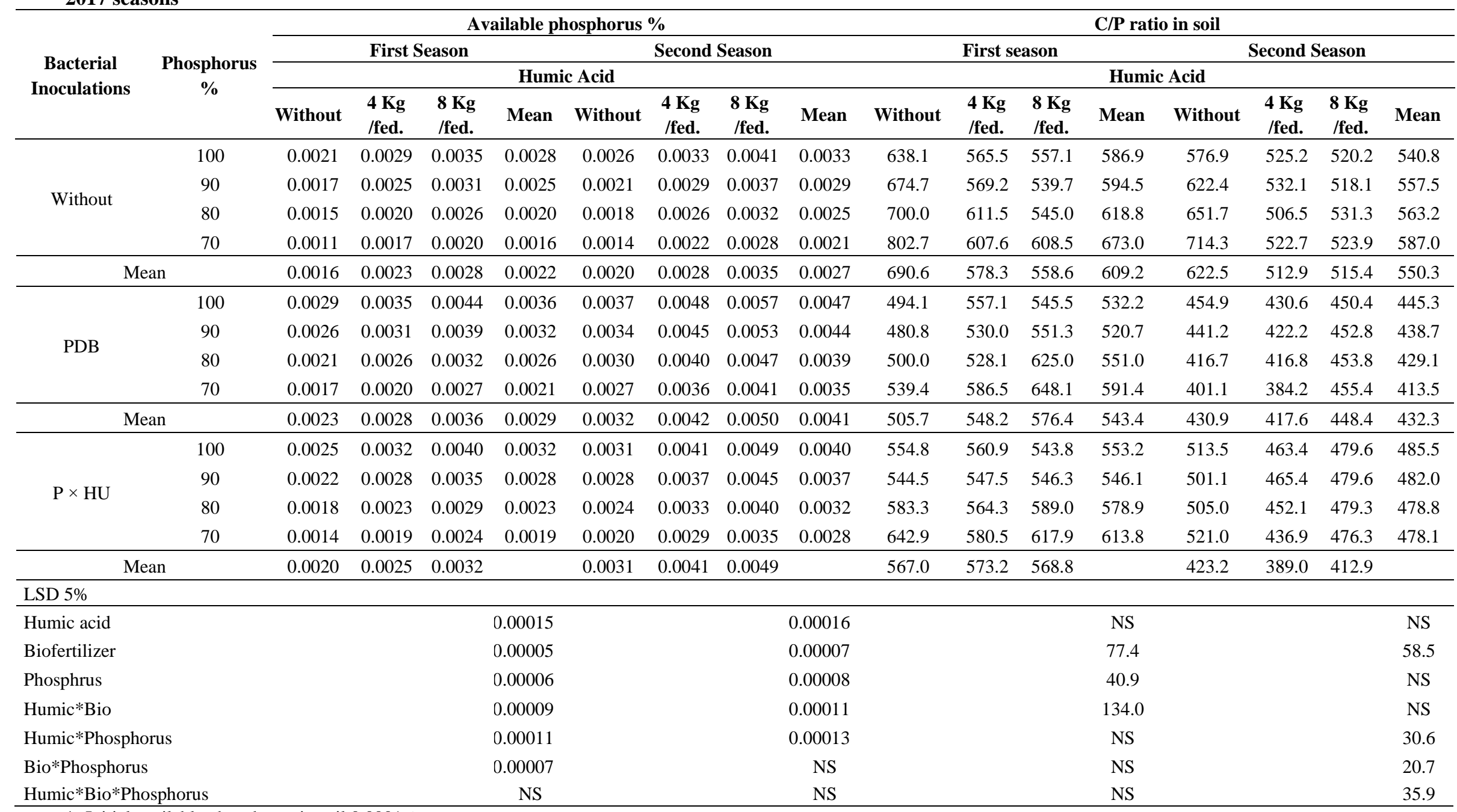

\footnotetext{
*- Initial available phosphorus in soil $0.0001 \%$

*- Initial C/P ratio in soil $8400 \%$

$*_{-} \mathrm{P} \times \mathrm{HU}=$ Interaction of Phosphorus treatment with humic acid treatments.

$*_{-} \mathrm{C} / \mathrm{P}$ ratio $=$ Organic Carbon \% / Available phosphorus \%
} 


\section{Pant growth:}

Data concerned with the effect of humic acid, biofertilizers and phosphate application on plant measurements expressed as plant height $(\mathrm{cm})$, number of branches, fresh weight, dry weight, number of leaves, chlorophyll, number of dry pods, length of pods, diameter of pods, average seed number, average weight of seeds and weight of seed yield of both investigated seasons were presented in Tables $(6-8)$. Obtained results indicated significant positive effect for either humic acid, biofertilizers and phosphorus application on the investigated characters; the highest values were obtained with $8 \mathrm{~kg}$ humic acid, PDB inoculation and $100 \%$ of phosphorus recommended dose $(200 \mathrm{~kg}$ superphosphate / fed).

Multiple regression was, also, carried out between plant dry weight, the most expressive growth parameter, on total microbial count and total microbial count without Bacillus megaterium and presented in equations (3 and 4). Regression coefficients indicated that plant dry weight (gm /plant) was increased in the first season an average of 0.00533 ( $\mathrm{gm} / \mathrm{plant}$ ) for each unit of total microbial count, but only by 0.00012 for each unit of total microbial count without Bacillus megaterium. The corresponding values in the second were 0.00927 and 0.000113 . This means that total microbial was more effective than total microbial count without Bacillus megaterium; in the same time indicated that total microbial count without Bacillus megaterium increased plant dry weight which could lead to conclude that microbial inoculation is very important in new reclaimed lands. Such conclusion was true in both investigated seasons.

$$
\mathrm{Y}^{\wedge}=82.7+0.00533 * \mathrm{X}_{1}+0.00012 * \mathrm{X}_{2} \text { Equation (3) }
$$

for the first season

$$
\mathrm{Y}^{\wedge}=120+0.00927 * \mathrm{X}_{1}+0.000113 * \mathrm{X}_{2} \text { Equation (4) }
$$

for the second season
Where Y stand for the dependent variable plant dry weigh (gm / plant), the independent variables $X_{1}$ stand for total microbial count (count $\times 10^{4} \mathrm{CFU}$ ) and $\mathrm{X}_{2}$ stand for total microbial count without Bacillus megaterium (count $\times 10^{4} \mathrm{CFU}$ )

Data showed that humic acid (8 kg/fed.), PDB inoculation and phosphate application (concentrion 100 $\%)$ gave the highest values of the investigated plant growth measurements in the first and second seasons. Ramana, V. et al. (2010) studied the effect of biofertilizers VAM (Vescicular Arbuscular Mycorrhizae) and PSB (Phosphorus Solubulizing Bactiria) along with their graded dose of fertilizers on growth of French bean. Their results revealed that the application of 75 per cent recommended Dose of Fertilizer + VAM + PSB significantly increased the plant height $(\mathrm{cm})$, number of branches per plant, leaf area $(\mathrm{cm} 2)$ and dry weight $(\mathrm{g})$ of plant. In addition, Yosefi et al. (2011) reported that biofertilizers improved soil fertility by fixing atmospheric nitrogen both in association with plant roots as well as solubilized insoluble soil phosphates and increased plant growth substances in the soil. Furthermore, Hala Kandil (2014) reported that pea growth as well as of other legumes was affected by both phosphorous and humic acid application. In this respect, Agamy et al. (2012) showed that the application of Bio and/or FM in combination with NPK on wheat (Triticum aestivum L.) significantly increased all growth characters i.e., plant height, number of spikes/plant, leaf area and fresh and dry weights of both shoot and spikes / plant. Shehata et al. (2006) added that there was some microorganism which stimulates the Azotobacter population in soil thereby increasing the nitrogen fixation by Azotobacter. They showed that the maximum increments of vine length and leaf number as well as fresh and dry weight of shoots were recorded by the inoculation of squash seeds with Azotobacter. Sarhan et al. (2011) added that Biogein and Netropein produced the intermediate values. 
Table 6. Influence of Humic acid, biofertilizers and phosphorus applications on plant height (cm) and number of branches /plant of pea during $2016 /$ 2017 seasons

\begin{tabular}{|c|c|c|c|c|c|c|c|c|c|c|c|c|c|c|c|c|c|}
\hline \multirow{4}{*}{$\begin{array}{c}\text { Bacterial } \\
\text { Inoculati } \\
\quad \text { ons }\end{array}$} & \multirow{4}{*}{$\begin{array}{l}\text { Phosphor } \\
\text { us \% }\end{array}$} & \multicolumn{8}{|c|}{ Plant height $(\mathrm{cm})$ of pea } & \multicolumn{8}{|c|}{ Number of branches /plant of pea } \\
\hline & & \multicolumn{4}{|c|}{ First Season } & \multicolumn{4}{|c|}{ Second Season } & \multicolumn{4}{|c|}{ First season } & \multicolumn{4}{|c|}{ Second Season } \\
\hline & & \multicolumn{8}{|c|}{ Humic Acid } & \multicolumn{8}{|c|}{ Humic Acid } \\
\hline & & $\begin{array}{c}\text { With } \\
\text { out }\end{array}$ & $\begin{array}{l}4 \mathrm{Kg} \\
\text { /fed. }\end{array}$ & $\begin{array}{l}8 \mathrm{Kg} \\
\text { /fed. }\end{array}$ & Mean & $\begin{array}{l}\text { With } \\
\text { out }\end{array}$ & $\begin{array}{l}4 \mathrm{Kg} \\
\text { /fed. }\end{array}$ & $\begin{array}{l}8 \mathrm{Kg} \\
\text { /fed. }\end{array}$ & Mean & $\begin{array}{c}\text { With } \\
\text { out }\end{array}$ & $\begin{array}{l}4 \mathrm{Kg} \\
\text { /fed. }\end{array}$ & $\begin{array}{l}8 \mathrm{Kg} \\
\text { /fed. }\end{array}$ & Mean & $\begin{array}{c}\text { With } \\
\text { out }\end{array}$ & $\begin{array}{l}4 \mathrm{Kg} \\
\text { /fed. }\end{array}$ & $\begin{array}{l}8 \mathrm{Kg} \\
\text { /fed. }\end{array}$ & Mean \\
\hline \multirow{4}{*}{ Without } & 100 & 42.7 & 55.7 & 60.9 & 60.9 & 46.3 & 67.1 & 70.9 & 70.9 & 8.7 & 15.3 & 13.4 & 13.4 & 12.3 & 26.3 & 24.4 & 24.4 \\
\hline & 90 & 41.3 & 54.3 & 59.8 & 59.8 & 44.9 & 65.3 & 67.8 & 67.8 & 8.3 & 15.0 & 12.8 & 12.8 & 10.7 & 23.7 & 21.9 & 21.9 \\
\hline & 80 & 40.3 & 52.7 & 58.2 & 58.2 & 43.1 & 62.2 & 65.0 & 65.0 & 8.0 & 14.3 & 12.3 & 12.3 & 9.3 & 20.7 & 19.6 & 19.6 \\
\hline & 70 & 38.7 & 50.7 & 56.6 & 56.6 & 42.2 & 58.6 & 62.5 & 62.5 & 7.3 & 12.7 & 11.2 & 11.2 & 8.0 & 18.7 & 17.0 & 17.0 \\
\hline \multicolumn{2}{|c|}{ Mean } & 40.8 & 53.3 & 82.5 & 58.9 & 44.1 & 63.3 & 92.2 & 66.5 & 8.1 & 14.3 & 14.9 & 12.4 & 10.1 & 22.3 & 29.8 & 20.7 \\
\hline \multirow{4}{*}{ PDB } & 100 & 47.7 & 93.3 & 87.2 & 87.2 & 55.6 & 102.2 & 96.7 & 96.7 & 13.3 & 20.7 & 20.7 & 20.7 & 18.3 & 32.3 & 29.4 & 29.4 \\
\hline & 90 & 47.3 & 89.3 & 82.0 & 82.0 & 52.3 & 96.7 & 91.7 & 91.7 & 11.7 & 19.3 & 18.7 & 18.7 & 15.3 & 28.7 & 26.0 & 26.0 \\
\hline & 80 & 45.7 & 87.3 & 77.7 & 77.7 & 49.7 & 92.1 & 86.3 & 86.3 & 10.3 & 17.7 & 16.3 & 16.3 & 13.7 & 24.7 & 23.0 & 23.0 \\
\hline & 70 & 43.3 & 72.7 & 67.7 & 67.7 & 47.7 & 86.9 & 80.5 & 80.5 & 9.0 & 16.0 & 14.8 & 14.8 & 12.3 & 22.3 & 21.0 & 21.0 \\
\hline \multicolumn{2}{|c|}{ Mean } & 46.0 & 85.7 & 104.3 & 78.6 & 51.3 & 94.5 & 120.6 & 88.8 & 11.1 & 18.4 & 23.3 & 17.6 & 14.9 & 27.0 & 32.7 & 24.9 \\
\hline \multirow{4}{*}{$\mathrm{P} \times \mathrm{HU}$} & 100 & 45.2 & 74.5 & 74.1 & 74.1 & 51.0 & 84.7 & 83.8 & 83.8 & 11.0 & 18.0 & 17.1 & 17.1 & 15.3 & 29.3 & 26.9 & 26.9 \\
\hline & 90 & 44.3 & 71.8 & 70.9 & 70.9 & 48.6 & 81.0 & 79.7 & 79.7 & 10.0 & 17.2 & 15.7 & 15.7 & 13.0 & 26.2 & 23.9 & 23.9 \\
\hline & 80 & 43.0 & 70.0 & 67.9 & 67.9 & 46.4 & 77.1 & 75.7 & 75.7 & 9.2 & 16.0 & 14.3 & 14.3 & 11.5 & 22.7 & 21.3 & 21.3 \\
\hline & 70 & 41.0 & 61.7 & 62.1 & 62.1 & 44.9 & 72.7 & 71.5 & 71.5 & 8.2 & 14.3 & 13.0 & 13.0 & 10.2 & 20.5 & 19.0 & 19.0 \\
\hline \multicolumn{2}{|c|}{ Mean } & 43.4 & 69.5 & 93.4 & & 47.7 & 78.9 & 106.4 & & 9.6 & 16.4 & 19.1 & & 12.5 & 24.7 & 31.2 & \\
\hline \multicolumn{18}{|c|}{ LSD 5\% } \\
\hline \multicolumn{2}{|l|}{ Humic acid } & & & & 3.8 & & & & 3.7 & & & & 1.8 & & & & 1.3 \\
\hline \multicolumn{2}{|c|}{ Biofertilizer } & & & & 2.4 & & & & 2.5 & & & & 2.5 & & & & 0.5 \\
\hline \multicolumn{2}{|l|}{ Phosphrus } & & & & 3.4 & & & & 1.4 & & & & 1.4 & & & & 0.5 \\
\hline \multicolumn{2}{|l|}{ Humic*Bio } & & & & 4.1 & & & & 4.3 & & & & NS & & & & 0.8 \\
\hline \multicolumn{2}{|c|}{ Humic*Phosphorus } & & & & 5.9 & & & & 2.5 & & & & NS & & & & 0.8 \\
\hline \multicolumn{2}{|c|}{ Bio*Phosphorus } & & & & 4.0 & & & & 1.7 & & & & 1.7 & & & & 0.6 \\
\hline \multicolumn{2}{|c|}{$\begin{array}{l}\text { Humic*Bio*Phosphor } \\
\text { us }\end{array}$} & & & & 6.9 & & & & 2.9 & & & & NS & & & & 1.0 \\
\hline
\end{tabular}

\footnotetext{
$*_{-} \mathrm{P} \times \mathrm{HU}=$ Interaction of Phosphorus treatment with humic acid treatments.
} 
Table 7. Influence of humic acid, biofertilizers and phosphorus applications on fresh weight (g)/plant and dry weight (g)/plant during $2016 / 2017$ seasons

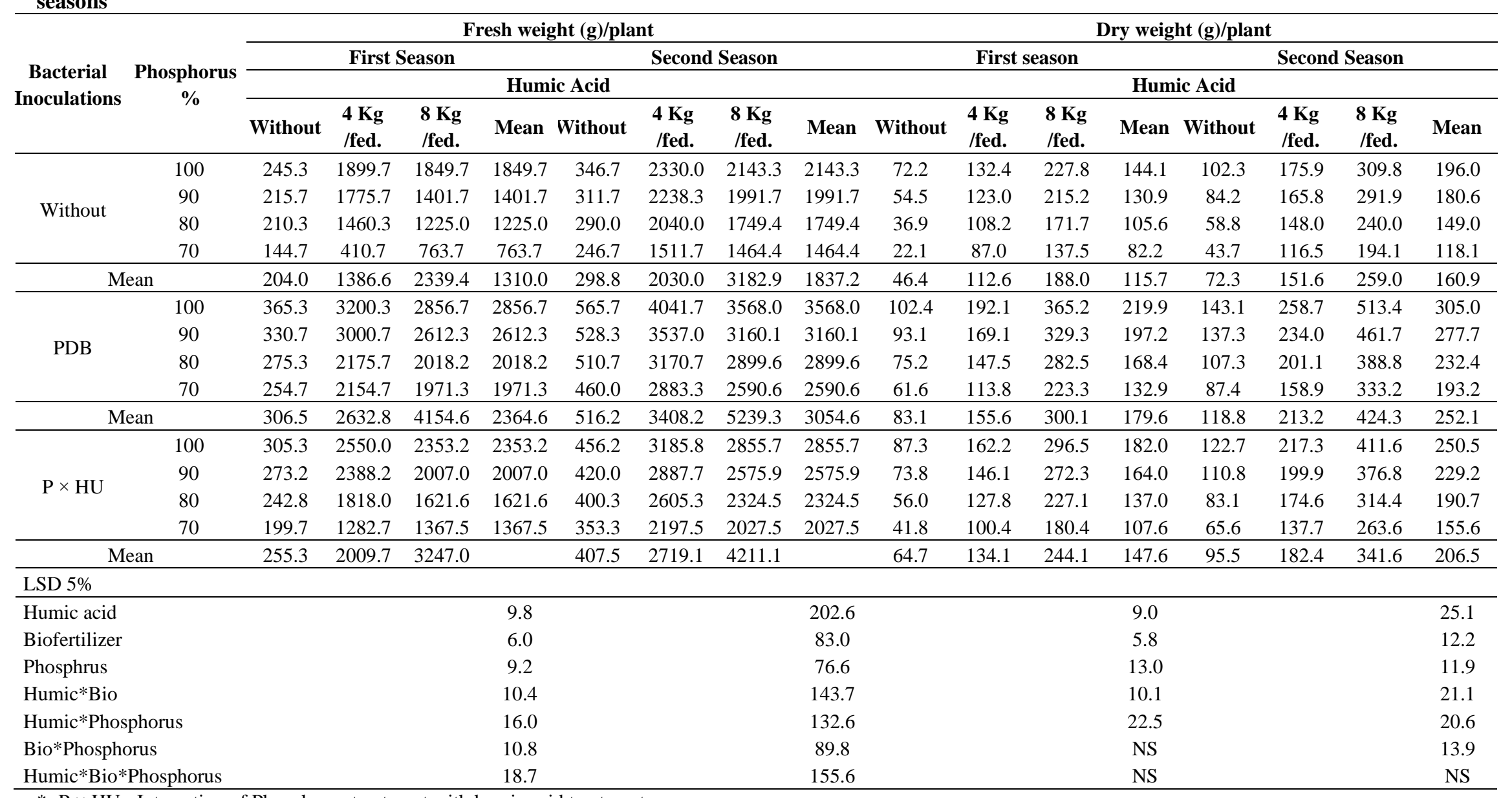

\footnotetext{
$*_{-} \mathrm{P} \times \mathrm{HU}=$ Interaction of Phosphorus treatment with humic acid treatments.
} 
Table 8. Influence of humic acid, biofertilizers and phosphorus applications on number of leaves /plant and chlorophyll (SPAD unit) during 2016/ 2017 seasons

\begin{tabular}{|c|c|c|c|c|c|c|c|c|c|c|c|c|c|c|c|c|c|}
\hline \multirow{4}{*}{$\begin{array}{c}\text { Bacterial } \\
\text { Inoculations }\end{array}$} & \multirow{4}{*}{$\begin{array}{c}\text { Phosphorus } \\
\%\end{array}$} & \multicolumn{8}{|c|}{ Number of leaves /plant } & \multicolumn{8}{|c|}{ Chlorophyll (SPAD unit) } \\
\hline & & \multicolumn{4}{|c|}{ First Season } & \multicolumn{4}{|c|}{ Second Season } & \multicolumn{4}{|c|}{ First season } & \multicolumn{4}{|c|}{ Second Season } \\
\hline & & \multicolumn{8}{|c|}{ Humic Acid } & \multicolumn{8}{|c|}{ Humic Acid } \\
\hline & & Without & $\begin{array}{l}4 \mathrm{Kg} \\
/ \text { fed. }\end{array}$ & $\begin{array}{l}8 \mathrm{Kg} \\
/ \text { fed. }\end{array}$ & Mean & Without & $\begin{array}{c}4 \mathrm{Kg} \\
\text { /fed. }\end{array}$ & $\begin{array}{c}8 \mathrm{Kg} \\
/ \text { fed. }\end{array}$ & Mean & Without & $\begin{array}{l}4 \mathrm{Kg} \\
/ \text { fed. }\end{array}$ & $\begin{array}{l}8 \mathrm{Kg} \\
/ \text { fed. }\end{array}$ & Mean & Without & $\begin{array}{c}4 \mathrm{Kg} \\
/ \text { fed. }\end{array}$ & $\begin{array}{l}8 \mathrm{Kg} \\
/ \text { fed. }\end{array}$ & Mean \\
\hline \multirow{4}{*}{ Without } & 100 & 14.3 & 28.0 & 26.6 & 26.6 & 21.7 & 33.0 & 33.2 & 33.2 & 19.3 & 23.0 & 39.0 & 27.1 & 22.3 & 26.5 & 43.1 & 30.6 \\
\hline & 90 & 12.7 & 24.3 & 22.8 & 22.8 & 19.0 & 28.7 & 29.4 & 29.4 & 17.7 & 18.3 & 35.6 & 23.9 & 19.6 & 23.7 & 40.1 & 27.8 \\
\hline & 80 & 11.3 & 22.3 & 20.1 & 20.1 & 16.7 & 24.7 & 26.4 & 26.4 & 14.9 & 14.4 & 29.3 & 19.5 & 16.8 & 19.0 & 35.4 & 23.7 \\
\hline & 70 & 9.7 & 18.0 & 17.7 & 17.7 & 13.3 & 21.7 & 23.2 & 23.2 & 12.9 & 10.9 & 23.0 & 15.6 & 14.6 & 14.7 & 28.0 & 19.1 \\
\hline \multicolumn{2}{|c|}{ Mean } & 12.0 & 23.2 & 30.2 & 21.8 & 17.7 & 27.0 & 39.6 & 28.1 & 16.2 & 16.7 & 31.7 & 21.5 & 18.3 & 21.0 & 36.7 & 25.3 \\
\hline \multirow{4}{*}{ PDB } & 100 & 20.7 & 35.3 & 40.6 & 40.6 & 25.3 & 46.7 & 47.8 & 47.8 & 26.2 & 44.4 & 59.1 & 43.2 & 28.5 & 47.7 & 70.6 & 48.9 \\
\hline & 90 & 18.3 & 31.7 & 35.1 & 35.1 & 22.7 & 43.0 & 42.7 & 42.7 & 22.8 & 39.7 & 54.6 & 39.0 & 25.1 & 43.2 & 62.2 & 43.5 \\
\hline & 80 & 15.7 & 27.3 & 31.6 & 31.6 & 19.3 & 38.7 & 38.1 & 38.1 & 18.6 & 35.2 & 47.2 & 33.7 & 21.5 & 39.0 & 57.0 & 39.2 \\
\hline & 70 & 11.7 & 24.7 & 25.6 & 25.6 & 16.3 & 34.7 & 34.6 & 34.6 & 14.8 & 27.9 & 43.1 & 28.6 & 17.9 & 34.5 & 52.6 & 35.0 \\
\hline \multicolumn{2}{|c|}{ Mean } & 16.6 & 29.8 & 53.3 & 33.2 & 20.9 & 40.8 & 60.7 & 40.8 & 20.6 & 36.8 & 51.0 & 36.1 & 23.2 & 41.1 & 60.6 & 41.6 \\
\hline \multirow{4}{*}{$\mathrm{P} \times \mathrm{HU}$} & 100 & 17.5 & 31.7 & 33.6 & 33.6 & 23.5 & 39.8 & 40.5 & 40.5 & 22.8 & 33.7 & 49.0 & 35.2 & 25.4 & 37.1 & 56.8 & 39.8 \\
\hline & 90 & 15.5 & 28.0 & 28.9 & 28.9 & 20.8 & 35.8 & 36.1 & 36.1 & 20.2 & 29.0 & 45.1 & 31.5 & 22.3 & 33.5 & 51.2 & 35.7 \\
\hline & 80 & 13.5 & 24.8 & 25.8 & 25.8 & 18.0 & 31.7 & 32.3 & 32.3 & 16.7 & 24.8 & 38.3 & 26.6 & 19.2 & 29.0 & 46.2 & 31.5 \\
\hline & 70 & 10.7 & 21.3 & 21.6 & 21.6 & 14.8 & 28.2 & 28.9 & 28.9 & 13.8 & 19.4 & 33.0 & 22.1 & 16.2 & 24.6 & 40.3 & 27.0 \\
\hline \multicolumn{2}{|c|}{ Mean } & 14.3 & 26.5 & 41.7 & & 19.3 & 33.9 & 50.1 & & 18.4 & 26.7 & 41.4 & & 20.8 & 31.0 & 48.6 & \\
\hline \multicolumn{18}{|c|}{ LSD 5\% } \\
\hline \multicolumn{2}{|l|}{ Humic acid } & & & & 3.3 & & & & 3.8 & & & & 2.6 & & & & 1.3 \\
\hline \multicolumn{2}{|l|}{ Biofertilizer } & & & & 2.2 & & & & 3.2 & & & & 2.1 & & & & 0.6 \\
\hline \multicolumn{2}{|l|}{ Phosphrus } & & & & 1.3 & & & & 2.1 & & & & 1.7 & & & & 0.8 \\
\hline \multicolumn{2}{|l|}{ Humic*Bio } & & & & 3.7 & & & & 5.6 & & & & 3.7 & & & & 1.0 \\
\hline \multicolumn{2}{|c|}{ Humic*Phosphorus } & & & & 2.3 & & & & NS & & & & 3.0 & & & & 1.3 \\
\hline \multicolumn{2}{|c|}{ Bio*Phosphorus } & & & & 1.6 & & & & NS & & & & NS & & & & 0.9 \\
\hline \multicolumn{2}{|c|}{ Humic*Bio*Phosphorus } & & & & 2.7 & & & & NS & & & & NS & & & & 1.6 \\
\hline
\end{tabular}

\footnotetext{
$*_{-} \mathrm{P} \times \mathrm{HU}=$ Interaction of Phosphorus treatment with humic acid treatments.
} 


\section{Yield and its components:}

Data concerned with the effect of humic acid, biofertilizers and phosphate application on Yield measurements expressed as number of dry pods, length of pods, diameter of pods, average seed number, average weight of seeds and weight of seed yield were presented in Tables $(9$ - 11). Obtained results indicated significant positive effect of all of humic acid, biofertilizers and phosphorus application on the investigated characters; the highest values were obtained with $8 \mathrm{~kg}$ humic acid, PDB inoculation or $100 \%$ of phosphorus recommended dose $(200 \mathrm{~kg}$ superphosphate / fed). Data showed that humic acid (8 $\mathrm{kg} / \mathrm{fed}$.), PDB inoculation and phosphate application (100\% of recommended dose) gave the highest values. Numbers of dry pods were 14.427 and 16.158 , lengths of pods were 9.967 and $10.950(\mathrm{~cm})$, diameters of pea pods were 0.915 and $0.978(\mathrm{~mm})$, average seeds number per pod were 8.342 and 8.967 , average seeds weight per pod were 3.488 and $3.850(\mathrm{~g})$ and weight of seeds yield $/ \mathrm{m}^{2}$ was 1356.7 and $1356.7(\mathrm{~g})$ in the first and second seasons respectively.

As for the relationship of seed yield and bacterial counts, multiple regression of seed yield $\left(\mathrm{gm} / \mathrm{m}^{2}\right)$ on total microbial count and total microbial count without Bacillus megaterium was estimated and presented in equations (5 and 6). Regression coefficients indicated that seed yield was increased in the first season an average of $0.31157 \mathrm{gm} / \mathrm{m}^{2}$ for each unit of total microbial count but only by $0.00028 \mathrm{gm} / \mathrm{m}^{2}$ for each unit of total microbial count without Bacillus megaterium. The corresponding values in the second

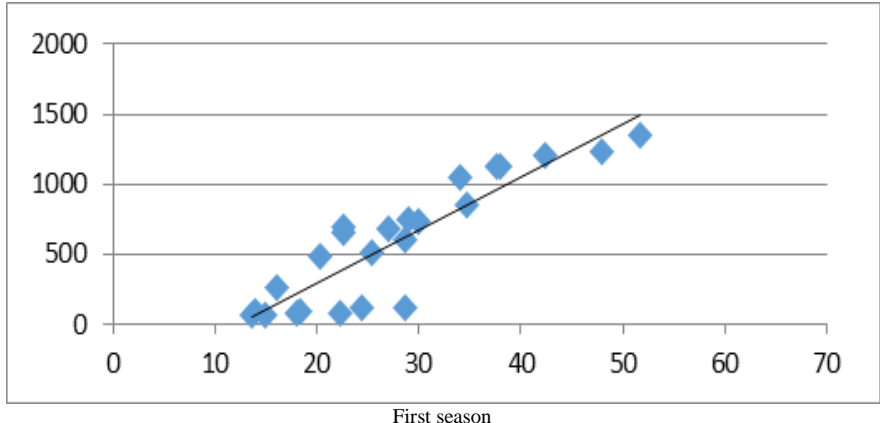

Fig. 2. Regression of seed yield $\left(\mathrm{Y}, \mathrm{gm} / \mathrm{m}^{2}\right)$ on Bacillus megaterium $\left(\mathrm{X}, \operatorname{count} \times 10^{4} \mathrm{CFU}\right)$

season were 0.393 and 0.00028 . This means that total microbial was more effective than total microbial count without Bacillus megaterium; in the same time indicated that total microbial count without Bacillus megaterium increased seed yield which could lead to conclude, again, that microbial inoculation is very important in new reclaimed lands for increasing seed yield. Such conclusion was true in both investigated seasons.

$\mathrm{Y}^{\wedge}=1012+0.31157 * \mathrm{X}_{1}+0.00028 * \mathrm{X}_{2}$ Equation (5) for the first season

$\mathrm{Y}^{\wedge}=1442+0.393 * \mathrm{X}_{1}+0.00028 * \mathrm{X}_{2}$ Equation (6) for the second season

Where $\mathrm{Y}$ stand for the dependent variable seed yield $\left(\mathrm{gm} / \mathrm{m}^{2}\right)$, the independent variables $\mathrm{X}_{1}$ stand for total microbial count (count $\times 10^{4} \mathrm{CFU}$ ) and $\mathrm{X}_{2}$ stand for total microbial count without Bacillus megaterium (count $\times 10^{4} \mathrm{CFU}$ ).

It is, also, of great interest to know the relation between Bacillus density (count $\times 10^{4)}$ and seed yield of pea plants. Linear correlation indicated that there was highly significant positive correlation between seed yield $\left(\mathrm{gm} / \mathrm{m}^{2}\right)$ and Bacillus megaterium density (count $\times 10^{4} \mathrm{CFU}$ ). Correlation coefficients (r) were 0.9 and 0.84 ) in the first and second seasons, respectively. Linear regression of seed yield on the independent variable showed that regression coefficients were 37.66 and 39.43 in the first and second seasons, respectively. This means that seed yield would increase by 37.66 and $39.43\left(\mathrm{gm} / \mathrm{m}^{2}\right)$ in the first and second seasons, respectively, for each unit increase of Bacillus megaterium

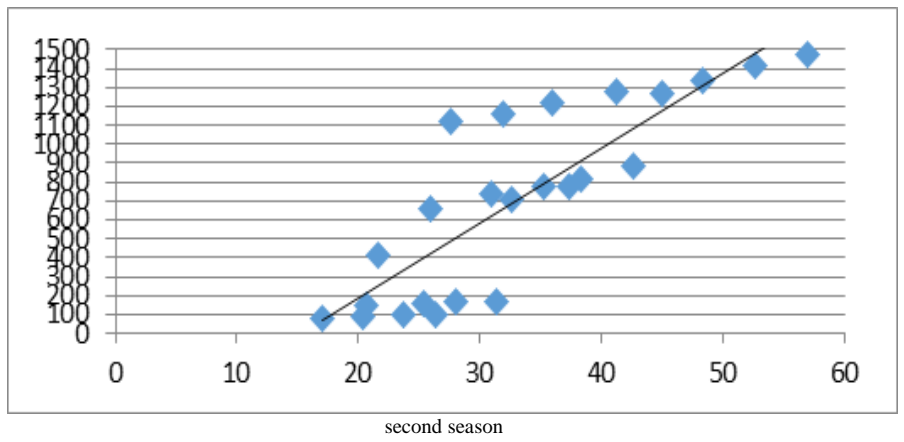

\footnotetext{
$+37.66 \mathrm{X}, \mathrm{r}=0.9$. in the 1_st season

$+39.43384 \mathrm{X}, \mathrm{r}=0.84$ in the 2_st season
} 
On the other hand, uninoculated treatment gave the lowest values of the qualities listed earlier as following: Number of dry pods / plant were 7.768 and 8.392, lengths of pods were 6.817 and $8.021(\mathrm{~cm})$, diameters of pea pods were 0.645 and $0.698(\mathrm{~mm})$, average seeds number / pod were 6.800 and 7.929 , average seeds weight / pod were 1.748 and $1.904(\mathrm{~g})$ and weights of seeds yield $/ \mathrm{m}^{2}$ were 730.7 and $803.3(\mathrm{~g})$ in the first and second season, respectively. That consistent with Afifi et al. (2010) results who found that humic acid improved nutrient status and yield components of faba bean plants. In addition, Ramana, V. et al. (2010) studied the effect of bio-fertilizers VAM (Vescicular Arbuscular Mycorrhizae) and PSB (Phosphorus Solubulizing Bactiria) along with their graded dose of fertilizers on yield attributes and yield of french bean. Their results revealed that the application of 75 per cent recommended Dose of Fertilizer + VAM + PSB significantly increased number of pods per plant, number of pods per cluster, number of seeds per pod, 100 seed weight $(\mathrm{g})$, pod length, pod yield per plant $(\mathrm{g})$ and pod yield per hectare. As for phosphorus effect on plant growth, Sharma (2002) reported that one of the advantages of plant feeding with phosphorus is to create deeper and more abundant roots. Omar et al. (1990) and Tesfaye et al. (2007) added that phosphorus is one of the most important elements significantly affecting plant growth and metabolism. The crop production on more than $30 \%$ of the world arable lands related to $\mathrm{P}$ availability. Tsvetkova and Georgiev, (2007) added that phosphorus may be a critical constraint of legumes under low nutrient environments because there is a substantial need for $\mathrm{P}$ in the $\mathrm{N}_{2}$ fixation process.

\section{Seed analysis:}

Regarding chemical constituents of pea seeds, nitrogen, phosphorus and potassium were estimated and shown in Tables $(12,13)$. It was clearly that pea plant treatments with only chemical fertilizers gave lower values than plants treated with biofertilizers in all the measurements in both investigated seasons. That result was in harmony with those obtained by El-Sayed et al. (2018 and Pandya and Saraf (2010). Also, Suke et al. (2011) reported that treated maize (Zea mays L.) with recommended dose fertilizer + Azotobacter + PSB led to increase of nitrogen, phosphorus and potassium contents in leaves.

\section{RECOMMENDATION}

The study revealed that using $8 \mathrm{~kg} \mathrm{HA} / \mathrm{fed}$ in combination with $\mathrm{PDB}$ and high level of $\mathrm{P}_{2} \mathrm{O}_{5}$ as a fertilizer application to improve soil properties, vegetative growth, mineral content and yield of pea plants in new soils was recommended. 
Table 9. Influence of humic acid, biofertilizers and phosphorus applications on number of dry pods /plant and length of pods (cm) of pea during 2016/ 2017 seasons

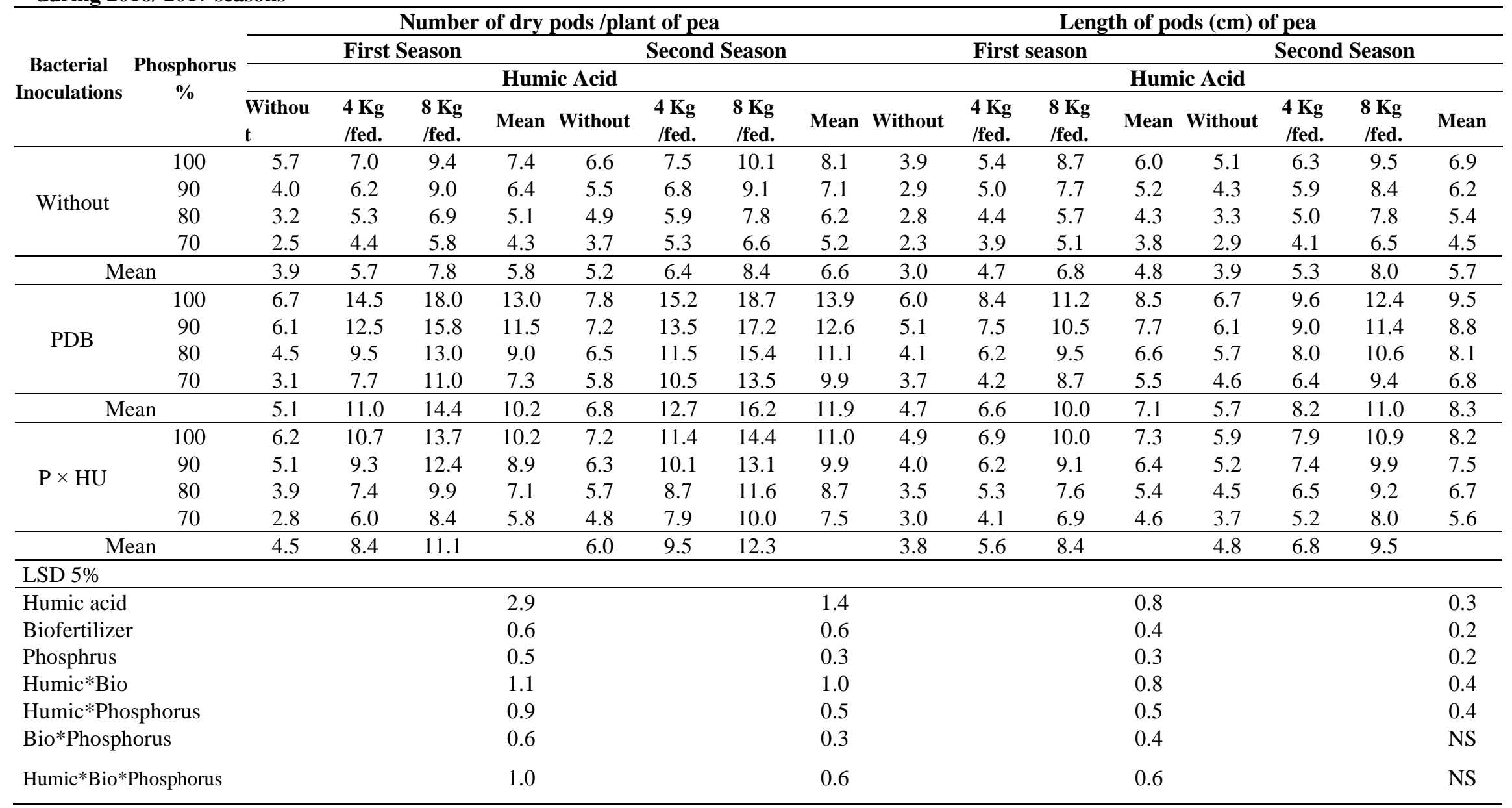

\footnotetext{
$*_{-} \mathrm{P} \times \mathrm{HU}=$ Interaction of Phosphorus treatment with humic acid treatments.
} 
Table 10. Influence of humic acid, biofertilizers and phosphorus applications on diameter of pods $(\mathrm{mm})$ of pea and average seed number /dry pod of pea during 2016/ 2017 seasons

\begin{tabular}{|c|c|c|c|c|c|c|c|c|c|c|c|c|c|c|c|c|c|}
\hline \multirow{4}{*}{$\begin{array}{c}\text { Bacterial } \\
\text { Inoculations }\end{array}$} & \multirow{4}{*}{$\begin{array}{c}\text { Phosphorus } \\
\%\end{array}$} & \multicolumn{8}{|c|}{ Diameter of pea pods $(\mathrm{mm})$} & \multicolumn{8}{|c|}{ Average seed number /dry pea pod } \\
\hline & & \multicolumn{4}{|c|}{ First Season } & \multicolumn{4}{|c|}{ Second Season } & \multicolumn{4}{|c|}{ First season } & \multicolumn{4}{|c|}{ Second Season } \\
\hline & & \multicolumn{8}{|c|}{ Humic Acid } & \multicolumn{8}{|c|}{ Humic Acid } \\
\hline & & Without & $\begin{array}{l}4 \mathrm{Kg} \\
/ \text { fed. }\end{array}$ & $\begin{array}{l}8 \mathrm{Kg} \\
/ \text { fed. }\end{array}$ & Mean & Without & $\begin{array}{l}4 \mathrm{Kg} \\
\text { /fed. }\end{array}$ & $\begin{array}{l}8 \mathrm{Kg} \\
/ \text { fed. }\end{array}$ & Mean & Without & $\begin{array}{l}4 \mathrm{Kg} \\
\text { /fed. }\end{array}$ & $\begin{array}{l}8 \mathrm{Kg} \\
/ \text { fed. }\end{array}$ & Mean & Without & $\begin{array}{l}4 \mathrm{Kg} \\
/ \text { fed. }\end{array}$ & $\begin{array}{l}8 \mathrm{Kg} \\
/ \text { fed. }\end{array}$ & Mean \\
\hline \multirow{4}{*}{ Without } & 100 & 0.37 & 0.57 & 0.71 & 0.55 & 0.52 & 0.63 & 0.78 & 0.64 & 4.05 & 5.61 & 7.85 & 5.84 & 4.78 & 6.52 & 9.07 & 6.79 \\
\hline & 90 & 0.32 & 0.52 & 0.67 & 0.50 & 0.41 & 0.57 & 0.72 & 0.57 & 3.48 & 5.35 & 7.02 & 5.28 & 4.38 & 5.95 & 8.45 & 6.26 \\
\hline & 80 & 0.28 & 0.46 & 0.63 & 0.46 & 0.35 & 0.49 & 0.68 & 0.51 & 3.68 & 4.90 & 6.52 & 5.03 & 3.85 & 5.25 & 7.52 & 5.54 \\
\hline & 70 & 0.23 & 0.37 & 0.57 & 0.39 & 0.26 & 0.42 & 0.61 & 0.43 & 3.27 & 4.52 & 5.82 & 4.54 & 3.52 & 4.77 & 6.68 & 4.99 \\
\hline \multicolumn{2}{|c|}{ Mean } & 0.30 & 0.48 & 0.65 & 0.48 & 0.38 & 0.53 & 0.70 & 0.54 & 3.62 & 5.09 & 6.80 & 5.17 & 4.13 & 5.62 & 7.93 & 5.89 \\
\hline \multirow{4}{*}{ PDB } & 100 & 0.48 & 0.87 & 1.02 & 0.79 & 0.61 & 0.96 & 1.16 & 0.91 & 4.71 & 7.25 & 9.18 & 7.05 & 5.98 & 8.65 & 9.88 & 8.17 \\
\hline & 90 & 0.44 & 0.82 & 0.94 & 0.73 & 0.52 & 0.88 & 0.99 & 0.80 & 4.63 & 6.62 & 8.92 & 6.72 & 5.35 & 7.67 & 9.43 & 7.48 \\
\hline & 80 & 0.37 & 0.75 & 0.88 & 0.67 & 0.46 & 0.84 & 0.91 & 0.74 & 4.31 & 6.28 & 8.08 & 6.23 & 4.78 & 6.95 & 8.70 & 6.81 \\
\hline & 70 & 0.34 & 0.67 & 0.83 & 0.61 & 0.38 & 0.75 & 0.86 & 0.66 & 3.78 & 5.90 & 7.18 & 5.62 & 3.88 & 6.02 & 7.85 & 5.92 \\
\hline \multicolumn{2}{|c|}{ Mean } & 0.41 & 0.78 & 0.92 & 0.70 & 0.49 & 0.86 & 0.98 & 0.78 & 4.36 & 6.51 & 8.34 & 6.40 & 5.00 & 7.32 & 8.97 & 7.10 \\
\hline \multirow{4}{*}{$\mathrm{P} \times \mathrm{HU}$} & 100 & 0.42 & 0.72 & 0.86 & 0.67 & 0.56 & 0.80 & 0.97 & 0.78 & 4.38 & 6.43 & 8.52 & 6.44 & 5.38 & 7.58 & 9.48 & 7.48 \\
\hline & 90 & 0.38 & 0.67 & 0.81 & 0.62 & 0.47 & 0.72 & 0.85 & 0.68 & 4.06 & 5.99 & 7.97 & 6.00 & 4.87 & 6.81 & 8.94 & 6.87 \\
\hline & 80 & 0.32 & 0.61 & 0.75 & 0.56 & 0.41 & 0.67 & 0.80 & 0.62 & 4.00 & 5.59 & 7.30 & 5.63 & 4.32 & 6.10 & 8.11 & 6.18 \\
\hline & 70 & 0.28 & 0.52 & 0.70 & 0.50 & 0.32 & 0.59 & 0.74 & 0.55 & 3.53 & 5.21 & 6.50 & 5.08 & 3.70 & 5.39 & 7.27 & 5.45 \\
\hline \multicolumn{2}{|c|}{ Mean } & 0.35 & 0.63 & 0.78 & & 0.44 & 0.69 & 0.84 & & 3.99 & 5.80 & 7.57 & & 4.57 & 6.47 & 8.45 & \\
\hline \multicolumn{18}{|l|}{ LSD 5\% } \\
\hline & & & & 0.03 & & & & 0.01 & & & & 0.45 & & & & 0.16 \\
\hline \multicolumn{2}{|l|}{ Biofertilizer } & & & & 0.01 & & & & 0.02 & & & & 0.25 & & & & 0.18 \\
\hline \multicolumn{2}{|l|}{ Phosphrus } & & & & 0.01 & & & & 0.02 & & & & 0.16 & & & & 0.17 \\
\hline \multicolumn{2}{|l|}{ Humic*Bio } & & & & 0.02 & & & & 0.04 & & & & 0.44 & & & & 0.32 \\
\hline \multicolumn{2}{|c|}{ Humic*Phosphorus } & & & & 0.02 & & & & NS & & & & 0.27 & & & & 0.29 \\
\hline \multicolumn{2}{|c|}{ Bio*Phosphorus } & & & & NS & & & & NS & & & & NS & & & & 0.20 \\
\hline \multicolumn{2}{|c|}{ Humic*Bio*Phosphorus } & & & & NS & & & & 0.04 & & & & NS & & & & 0.34 \\
\hline
\end{tabular}

\footnotetext{
$*_{-} \mathrm{P} \times \mathrm{HU}=$ Interaction of Phosphorus treatment with humic acid treatments.
} 
Table 11. Influence of humic acid, biofertilizers and phosphorus applications on average weight of seeds (g) /pod of pea and weight of seed yield (g)/m of pea during 2016/2017 seasons

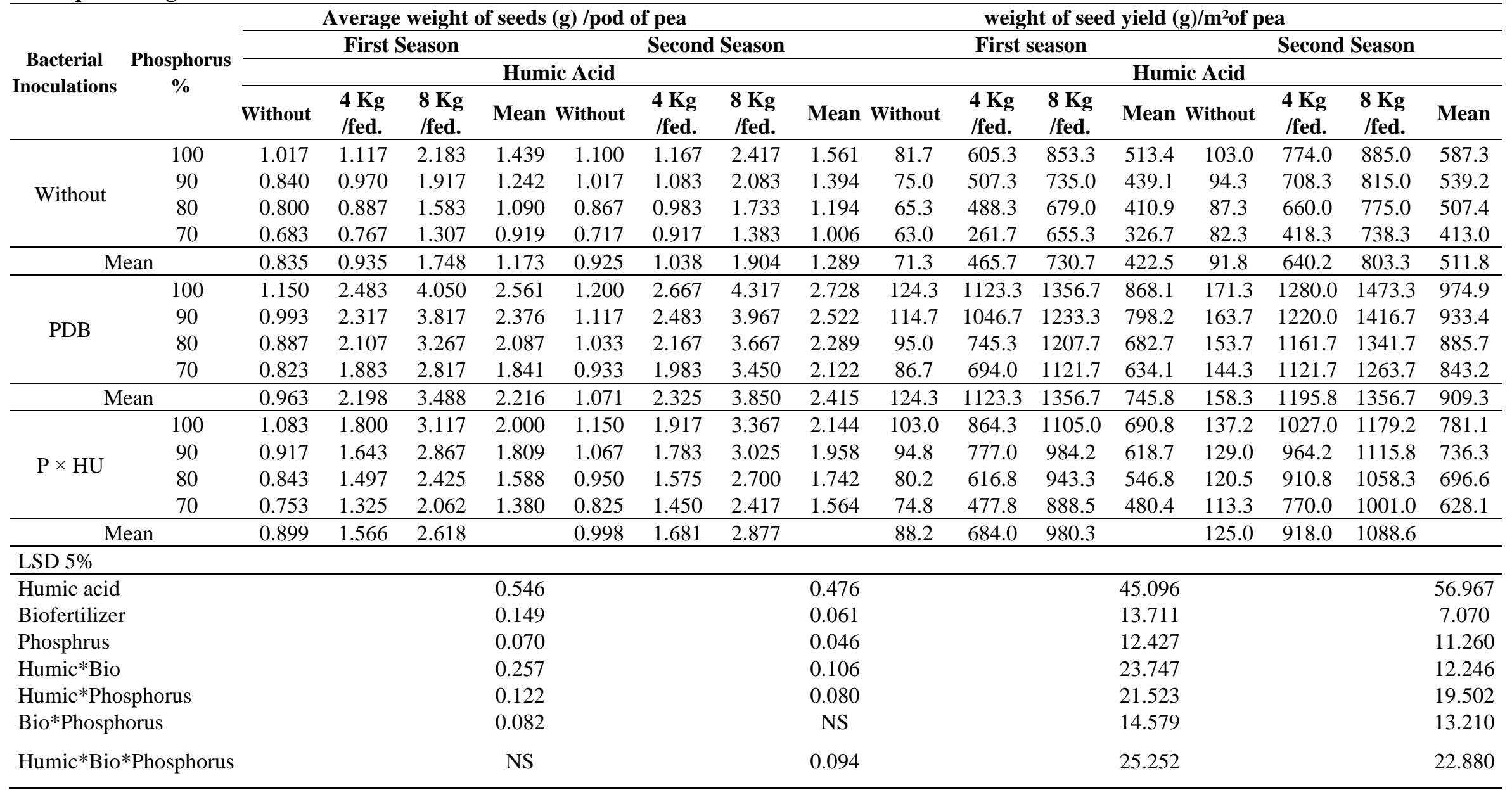

\footnotetext{
$*_{-} \mathrm{P} \times \mathrm{HU}=$ Interaction of Phosphorus treatment with humic acid treatments.
} 
Table 12. Influence of humic acid, biofertilizers and phosphorus applications on nitrogen and phosphorus concentration in seeds of pea during 2016/ 2017 seasons

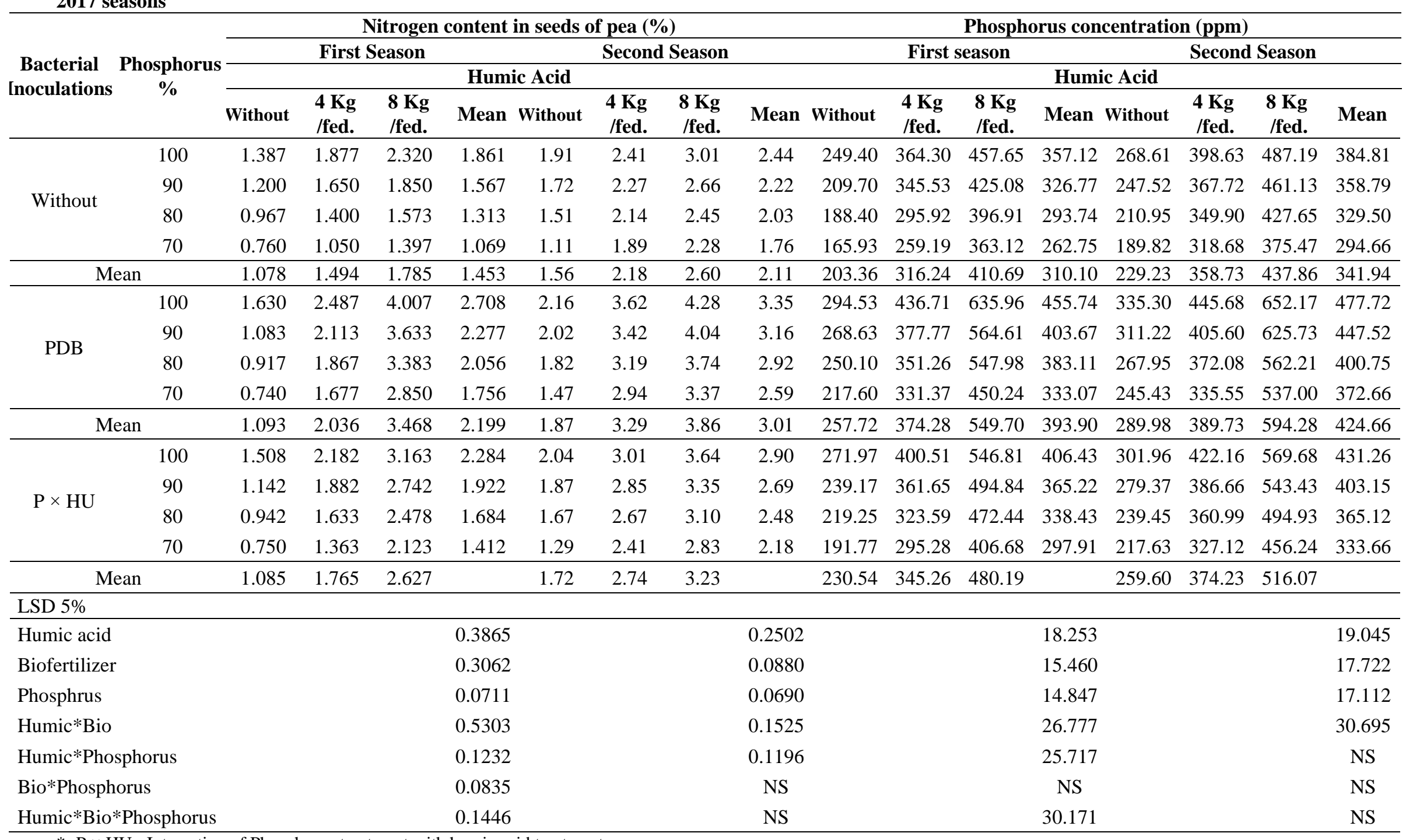

\footnotetext{
$*_{-} \mathrm{P} \times \mathrm{HU}=$ Interaction of Phosphorus treatment with humic acid treatments.
} 
Table 13. Influence of humic acid, biofertilizers and phosphorus applications on potassium concentration in seeds of pea during $2016 / 2017$ seasons

\begin{tabular}{|c|c|c|c|c|c|c|c|c|c|}
\hline \multirow{4}{*}{$\begin{array}{c}\text { Bacterial } \\
\text { Inoculations }\end{array}$} & \multirow{4}{*}{ Phosphorus } & \multicolumn{8}{|c|}{ Potassium concentration $(\%)$} \\
\hline & & \multicolumn{5}{|c|}{ First Season } & \multicolumn{2}{|c|}{ Second Season } & \\
\hline & & \multicolumn{8}{|c|}{ Humic Acid } \\
\hline & & Without & $4 \mathrm{Kg} / \mathrm{fed}$. & $8 \mathrm{Kg} / \mathrm{fed}$. & Mean & Without & $4 \mathrm{Kg} / \mathrm{fed}$. & $8 \mathrm{Kg} /$ fed. & Mean \\
\hline \multirow{4}{*}{ Without } & 100 & 0.91 & 1.28 & 1.37 & 1.19 & 1.38 & 1.76 & 1.94 & 1.69 \\
\hline & 90 & 0.84 & 1.18 & 1.28 & 1.10 & 1.14 & 1.40 & 1.70 & 1.41 \\
\hline & 80 & 0.77 & 1.11 & 1.24 & 1.04 & 1.01 & 1.17 & 1.42 & 1.20 \\
\hline & 70 & 0.73 & 1.02 & 1.14 & 0.97 & 0.94 & 1.05 & 1.19 & 1.06 \\
\hline \multicolumn{2}{|c|}{ Mean } & 0.81 & 1.15 & 1.26 & 1.07 & 1.12 & 1.35 & 1.56 & 1.34 \\
\hline \multirow{4}{*}{ PDB } & 100 & 1.13 & 1.66 & 2.02 & 1.60 & 1.73 & 2.12 & 2.56 & 2.13 \\
\hline & 90 & 1.08 & 1.54 & 1.95 & 1.52 & 1.47 & 1.85 & 2.28 & 1.87 \\
\hline & 80 & 1.03 & 1.45 & 1.86 & 1.45 & 1.17 & 1.49 & 1.98 & 1.55 \\
\hline & 70 & 0.92 & 1.31 & 1.74 & 1.33 & 1.05 & 1.34 & 1.78 & 1.39 \\
\hline \multicolumn{2}{|c|}{ Mean } & 1.04 & 1.49 & 1.89 & 1.47 & 1.36 & 1.70 & 2.15 & 1.74 \\
\hline \multirow{4}{*}{$\mathrm{P} \times \mathrm{HU}$} & 100 & 1.02 & 1.47 & 1.69 & 1.40 & 1.55 & 1.94 & 2.25 & 1.91 \\
\hline & 90 & 0.96 & 1.36 & 1.61 & 1.31 & 1.31 & 1.63 & 1.99 & 1.64 \\
\hline & 80 & 0.90 & 1.28 & 1.55 & 1.24 & 1.09 & 1.33 & 1.70 & 1.37 \\
\hline & 70 & 0.83 & 1.17 & 1.44 & 1.15 & 1.00 & 1.19 & 1.49 & 1.22 \\
\hline \multicolumn{2}{|c|}{ Mean } & 0.93 & 1.32 & 1.58 & & 1.24 & 1.52 & 1.86 & \\
\hline \multicolumn{10}{|l|}{ LSD 5\% } \\
\hline \multicolumn{2}{|l|}{ Humic acid } & & & & 0.033 & & & & 0.069 \\
\hline \multicolumn{2}{|l|}{ Biofertilizer } & & & & 0.016 & & & & 0.149 \\
\hline \multicolumn{2}{|l|}{ Phosphrus } & & & & 0.023 & & & & 0.083 \\
\hline \multicolumn{2}{|l|}{ Humic*Bio } & & & & 0.028 & & & & NS \\
\hline \multicolumn{2}{|c|}{ Humic*Phosphorus } & & & & 0.040 & & & & NS \\
\hline \multicolumn{2}{|c|}{ Bio*Phosphorus } & & & & 0.027 & & & & NS \\
\hline \multicolumn{2}{|c|}{$\begin{array}{l}\text { Humic*Bio*Phosphor } \\
\text { us }\end{array}$} & & & & NS & & & & NS \\
\hline
\end{tabular}

$*_{-} \mathrm{P} \times \mathrm{HU}=$ Interaction of Phosphorus treatment with humic acid treatments.

\section{REFERENCE}

A.O.A.C. 1990. Official Methods of Analysis Association of Officinal Analytical Chemists $16^{\text {th }}$ Ed. Washington. D.C. U.S.A.

Abdel-Hafez, A.M. 1966. Some studies on acid producing microorganisms in soil and rhizosphere with special reference to phosphate dissolvers. Ph. D Thesis Fac. Agric. Ain shams Univ., Cairo, Egypt.

Abdel-Kader, A.A.S. and F.E.M. Saleh. 2017. Improvement of yield and quality of Roselle (Hibiscus Sabdariffa 1.) Plant by using natural sources of phosphorus and potassium in calcareous sandy soils Scientific J. Flowers and Ornamental Plants. 4(3):233-244.

Afifi, M.H.M., M.F. Mohamed and H.A. Shaaban. 2010. Yield and nutrient uptake of some faba bean varieties grown in newly cultivated soil as affected by foliar application of humic acid. J. of Plant Production. 1(1):77-85.

Agamy, R.A., G.F. Mohamed and M.M. Rady. 2012. Influence of the Application of Fertilizer type on Growth, yield, anatomical structure and some chemical components of Wheat (Triticum aestivum L.) Grown in
Newly Reclaimed Soil. Australian J. of Basic and Applied Sci. 6(3): 561-570.

Albayrak, S.C. 2005. Effects of different levels and application times of humic acid on root and leaf yield and yield components of forage turnip (Brassica rapa L.). J. Agron. 4 (2): 130-133.

Al-Haddad, Z.K. and A. Sh. Soliman. 2014. Effect of Different Bio Fertilizers and Soil Media on Growth and Chemical Composition of Eucalyptus camaldulensis in North Africa. J. of Horticultural Sci. \& Ornamental Plants. 6 (2): 5970.

Allen, I. N. 1959. Experiments in soil bacteriology. Burgess Publishing Co., Minneapolis, Minnesota, U.S.A.

Amal, A., E. Wedad, A.M. Heggo and A.H. Enas. 2014. Effect of dual inoculation with arbuscular mycorrhizal fungi and sulphur-oxidising bacteria on onion (Allium cepa L.) and maize (Zea mays L.) grown in sandy soil under green house conditions. Annals of Agricultural Sci. 59: 109-118.

Amal, M. O. 2010. Bioformulations of Bacillus Spores for using as Biofertilizer, Life Sci. J. 7(4):124-131. 
Ashraf, M.W., N. Saqib, T.B. Sarfraz. 2005. Biological effect of bio-fertilizer humic acid on mung beans (Vigna radiate L.). J. Bio. Biotech. 2 (3): 737- 739.

Babulkar, P.S., R.M. Wandile, W.P. Badole and S.S. Balpande. 2000. Residual effect of long term application of FYM and fertilizers on soil properties and yield of soybean. J. Indian Soc. Soil Sci. 48(1):89-92.

Bogatyre, A.N. 2000. What are we to eat or how to live longer? Pishchevaya Promyshlennost. 7:34-35.

El-Gizawy, N. Kh. B. 2009. Effect of planting date and fertilizer application on yield of wheat under no. till sytem. World J. of Agriculture Sci. 5(6): 777- 783.

El-Sayed, M.A.M., M.F. Attia and M.R Hafez. 2018. Effect of Natural and Bio-Fertilizers on Productivity and Quality of Table Beet (Beta vulgaris L.) Grown in Sandy Soil at Siwa Oasis, Egypt. Alexandria, Sci. Exc. J. 39(4): 722-738.

Eman, Abdel-Monem A.A., M.M.S. Saleh and E.A.M. Mostafa. 2008. Miniizing the quantity of mineral nitrogen fertilizers on grapevine by using humic acid, organic and bio-fertilizers. Research J. of Agric. and Biological Sci. 4 (1): 4650 .

Erik, B.G.F., C.C. Shock and L.D. Saunders. 2000. Evaluation of humic acid and other non conventional fertilizer additives for mustard production. Malheur Experimental Station, Oregon State University, Ontario. pp. 115

Eweda, W.E., S.M. Selim, M.I. Mostafa and D.A. Abd ElFattah. 2007. Use of Bacillus circulans as bio-accelerator enriching composted Agricultural wastes identification and utilization of the microorganism for compost production. In: Proceedings of the $12^{\text {th }}$ Conference of the Microbiology. Organized by The Egyptian Soc. of App. Micro. (ESAM), Giza, Egypt. 18-20 pp. 43-65.

Girgis, M.G.Z. 2006. Response of wheat to inoculation with phosphate and potassium mobilizers and organic amendment.Annals Agric. Sci., Ain Shams Univ., Cairo. 51(1): 85-100.

Hala, K. 2014. Response of pea plants (Pisum sativum L.) to phosphorus levels and humic acid levels. International Conference of Agricultural Engineering - AgEng 6-10 July Zurich, P0136.

Han, H.S. and K.D. Lee. 2005. Physiological responses of soybeanInoculation of Bradyrhizobium japonicum with PGPR in saline soil conditions. Res. J. Agric. Biol. Sci. 1(3): 216-221.

Hilda, R., R. Fraga. 1999. Phosphate solubilizing bacteria and their role in plant growth promotion. Biotechnol. Adv. 17:319-339.

Jackson, M .L. 1973. Soil chemical analysis, prentice Hall of India Pvt. Ltd., New Delhi.

Keeling, A.A., K.R. McCallum and C.P. Beckwith. 2003. Crop and Environment Research Centre, Harper Adams University College, Newport, Shropshire, UK, Bioresource Tech. 90(2): 127-137.

Khan, M.J., M.T. Jan and K. Khan. 2013. Effect of organic and inorganic amendments on the heavy metal content of soil and wheat crop irrigated with wastewater. Sarhad J. Agric. 29(1): 49-57.
Klute, A.A. 1986. "Methods of soil analysis" Part " 1 " $2^{\text {nd }}$ edition, American Society of Agronomy. Inc., Publisher, Madison, Wisconsin, U.S.A.

Kucey, R.M.N., H.H. Jenzen and M.E. Leggett. 1989. Microbially mediated increases in plant available phosphorus. Adv. Agron. 42:199-228.

Leisinger, K.M. 1999. Biotechnology and food security, Curr. Sci. India. 76:488-500.

Lin, Q.M., Z.H. Rao, Y.X. Sun, J. Yao and L.J. Xing. 2002. Identification and practical application of silicatedissolving bacteria. Agric. Sci. China. 1:81-85.

Luo, Y., X. Zhou. 2006. Soil Respiration and the Environment. Academic Press and Elsevier Inc., Burlington.

Mackowiak, C., P. Grossl and B. Bugbee. 2001. Beneficial effects of humic acid on micronutrient availability to wheat. Soil Sci. Soc. Am. J. 65 (6): 1744-1750.

Mart, I. 2007. Fertilizers, organic fertilizers, plant and agricultural fertilizers. Agro and Food Business Newsletter. pp. 1-4.

Mauromicale, G., M.G.L. Angela and A.L. Monaco. 2011. The effect of organic supplementation of solarized soil on the quality of tomato. Scientia Hort. 129 (2): 189-196.

McLean, E.O. 1982. Soil pH and lime requirement. In: A. L. Page, R. H. Miller and D. R. Keeney (eds.) Methods of Soil Analysis. Am. Soc. Agronm. and Soil. Sci. Soc. Am. Madison, WI. USA:199- 224.

Mikkelsen, R.L. 2005. Humic materials for agriculture, Davis, California, USA. Better Crops with Plant Food. 89 (3): 67.

Mohamed, A., A. Bakry, Y.R.A. Soliman and S.A.M. Moussa. 2009. Importance of micronutrients, organic manure and bio-fertilizer for improving maize yield and its components grown in desert sandy soil. Res. J. Agric. Bio. Sci. 5 (1): 16-23.

Muscolo, A., M. Sidari and E. Attina. 2007. Biological activity of humic substances is related to their chemical structure. Soil Sci. Soc. Amer. J. 71: 75-85.

Nardi, S., D. Pizzeghello, A. Muscolo and A. Vianello. 2002. Physio logical effects of humic substances in plant growth. Soil Biol. Biochem, Exeter. 34: 1527-1537.

Nardi, S., D. Pizzeghello and S.G. Pandalai. 2004. Rhizosphere: A communication between plant and soil. Recent Res. Dev. in Crop Sci. 1 (2): 349-360

Olsen, S.R., C.J.Cole, F.S. Watanabe and L.A. Dean. 1982. Estimation of available phosphorus in soils by extraction with sodium bicarbonate. Circ. No. 939. USDA. U.S. Government Printing Office, Washington.DC.

Omar, N.M., A.M. Shaheen and M.O. Bakry. 1990. The residual effect of sulphur and phosphorus ation on the growth yield of pea (Pisum sativum L.) plants. Egypt J. Agron. 15 (1-2):87.

PalSS. 1998. Interactions of an acid tolerant strain of phosphate solubilizing bacteria with a few acid tolerant crops. Plant and Soil. 198:169-177. 
Pandya, U. and M. Saraf. 2010. Application of fungi as a bio control agent and their bio fertilizer potential in agriculture. J. Advan. Develop. And Res. 1(1): 90-99.

Peach, K. and M. V. Tracey. 1956. Modern methods of combination of pig slurry and mineral nitrogen fertilizer. J. Agric. Sci. Camb. 127: 151 -159.

Pramer, D. and E.L. Schmidt. 1994. Experimental Soil Microbioligy. pp. 235 -237 Burgerss Publishing Co., Minnesota. USA.

Ramana, V. R., M. K. Purushotham and K. R. Balakrishna. 2010. Effect of biofertilizers on growth, yield attributes and yield of French Bean (PHASEOLUS VULGARIS L.) Legume Res. 33 (3): 178 - 183.

Rodríguez, H. and R. Fraga. 1999. Phosphate-solubilizing bacteria and their role in plant growth promotion. Biotech. Adv. 17:319-339.

Sahin, F., R. Çakmakçi and F. Kantar. 2004. Sugar beet and barley yields in relation to inoculation with $\mathrm{N}$-fixing and phosphate solubilizing bacteria. Plant Soil. 2 (265): 123129.

Sarhan, T. Z., G.H. Mohammed and J.A.Teli. 2011. Effect of bio and organic fertilizers on growth, yield and fruit quality of summer squash. Sarhad J. Agric. 27 No.3.

Sarir, M.S., M. Sharif, Z. Ahmed and M. Akhlaq. 2005. Influence of different levels of humic acid application by various methods on the yield and yield components of maize. Sarhad J. Agric. 21 (1): 75-81.

Sarwar, M., S.I. Hyder and A. M. Ehsan. 2014. Integrated effects of humic acid and bio fertilizer on yield and phosphorus use efficiency in mungbean under rainfed condition; World J. of Agricultural Sci. 2 (3):040-046.

Sharma, A.K. 2002. Bio-fertilizers for sustainable agriculture. Agrobios Indian publications.

Shehata, S.M., S.A. Saleh and H. Junge. 2006. Response of sexual excretion and productivity of squash plants to some bio fertilizer treatments. FZB Biotechnik GmbH,Glienicker Weg 185,D 12489 Berlin,Gemany.

Snedecor, G. W. and W. G. Cochran. 1989. Statistical methods, $8^{\text {th }}$ Ed., Iowa state Univ., press, Iowa. U. S. A.

Suke, S.N., R.D. Deotale, H. Priyanka, D. Mitali and S.N. Sorte. 2011. Effect of nutrients and biofertilizers of chemical and biochemical parameters of maize (Zea mays L.).J. Soil and Crops. 21(1):107-112.
Susilawati, K., O. H. Ahmed, A. M. Nik Muhammad and M. Y. Khanif. 2009. Effect of organic based $\mathrm{N}$ fertilizer on dry matter (Zea mays L.), ammonium and nitrate recovery in an acid soil of Sarawak, Malaysia. Am. J. Applied Sci. 6 (7): 1282-1287.

Tabatabai, M.A. and J.M. Bremner. 1969. Use of Pnitrophenol phosphate for assay of soil phosphatase activity. Soil Biol. Biochem. 1: 301-307.

Tesfaye, M., J. Liu, D.L. Allan and C.P. Vance. 2007. Genomic and genetic control of phosphate stress in legumes. Plant Physiol. 144:594- 603.

Thalmann, A. 1967. Uber die microbiello Akivitat undihr Beziehung $\mathrm{Zu}$ fruchtbartkeits merkmalen eini-ger Acherboden unter besonderer Berucksi chtigung der dehydrogenase akativitat (TTC. Redukation). Biss Gieben PH.D.Thesis.W. Germany.

Tsvetkova, G.E. and G.I. Georgiev. 2007. Changes in phosphate fractions extracted from different organs of phosphorus starved nitrogen fixing pea plants. J. Plant Nutr. 30:2129-2140.

Vasil, I.K. 1998. Biotechnology and Food security for 21st century: A real world perspective, Nat. Biotechnol. 16: 399-400.

Vetayasuporn, S. 2006. Effects of biological and chemical fertilizers on growth and yield of glutinous corn production. J. Agron. 5 (1): 1-4

Vikram, A. and H. Hamzehzarghani. 2008. Effect of phosphate solubilizing bacteria on nodulation and growth parameters of green gram (Vigna radiate L. Wilchek). Res. J. Microbiol. 3:62-72.

Walkley, A. and I. A. Black. 1934. An Examination of Degtjareff Method for Determining Soil Organic Matter and a Proposed Modification of the Chromic Acid Titration Method. Soil Sci. 37:29-37.

Yagodin, B.A. 1990. Agricultural chemistry. Mir Publishers Moscow.278-281.

Yosefi, K., M. Galavi, M. Ramrodi and S.R. Mousavi. 2011. Effect of bio-phosphate and chemical phosphorus fertilizer accompanied with micronutrient foliar application on growth, yield and yield components of maize. Aus. J. Crop Sci. 5(2):175-180.

Zhang, X. and E.H. Ervin. 2004. Cytokinin-containing seaweed and humic acid extracts associated with creeping bentgrass leaf cytokining and drought resistance. Crop Sci. 44: 1737-1745. 


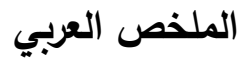

\section{تأثير حامض الهيوميك والأسمدة الحيوية والفوسفات المعدنى على النشاط الميكروبى بالتربة

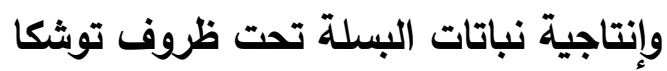 \\ محمود على محمد السيد، السيد محمد طه لهال}

مقارنة بنتائج إستخدام خليط من حامض الكيوميك والسوبر فوسفات فقط. كما أشارت الدراسة أيضا الى أن معدلات الإضافة من حامض الكيوميك والسوبر فوسفات مع وجود البكتريا المذيبة للفوسفات أدت الى تحسين معظم صفات

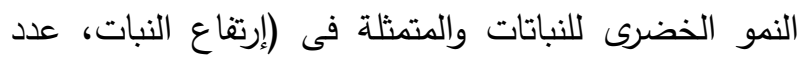

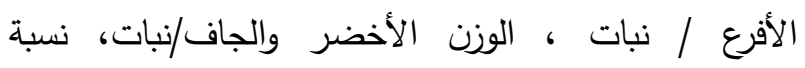

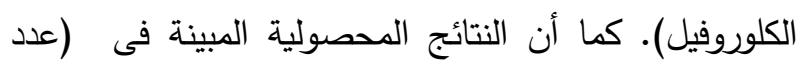
القرون الجافة على النبات، طول القرن/سم، قطر القرون

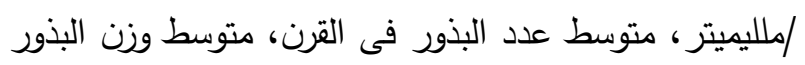

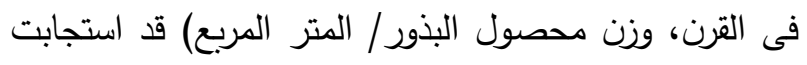

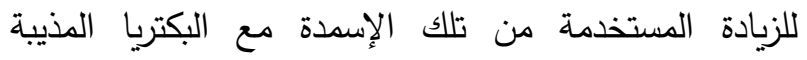

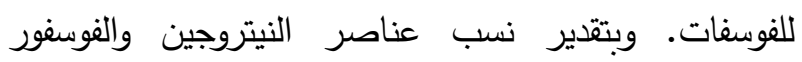

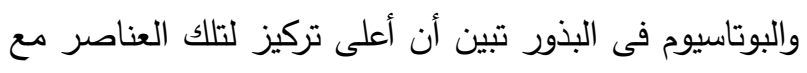
إستخدام حامض الهيوميك (^ كجم/ فدان) مصحوبا بالتلقيح

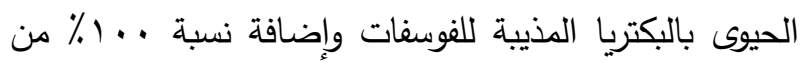
التسميد الفوسفاتى فو بأ الموصى به فى الإنتاج التجاري. أوصت الدراسة بموجب هذا التطبيق باستخدام + PDB + والنمو الخضرى والمحتوى المعدني والناتج المحصولى لنباتات البسلة فى الأراضى الحديثة.
أجريت دراسة حقلية خلال الموسم الثتوى لعامي

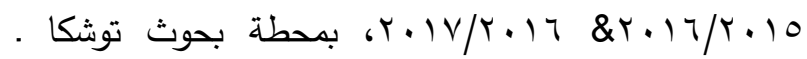

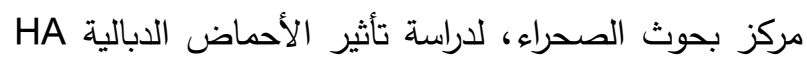

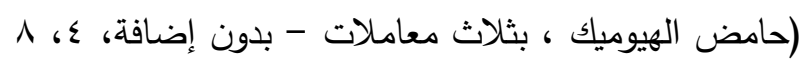

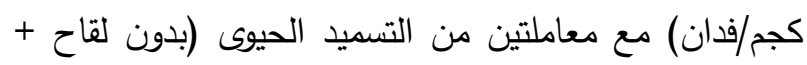

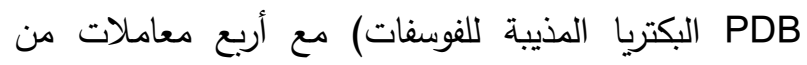

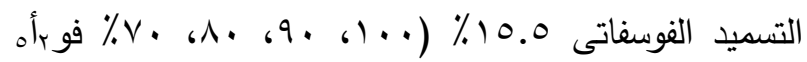
من المعدل الموصى به فى الإنتاج التجارى) على نباتات

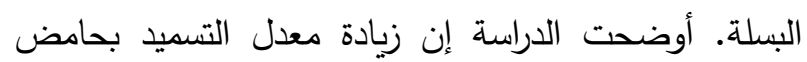

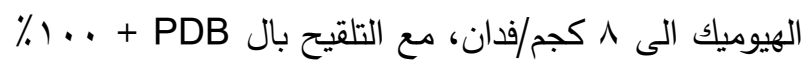

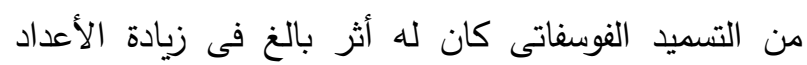
الكلية للميكروبات والبكتريا الدذيبة للفوسفات وإنبعاث ثانى

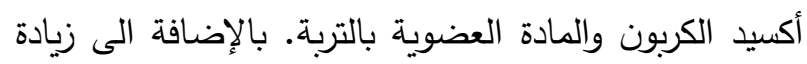
نثاط الإنزيمات المرتبطة بميكروبات التربة مثل إنزيم الفوسفاتيز والديهيدروجنيز. كما أن المحتوى المعدنى فى التى التيكات التربة مثل النيتروجين الكلى والفوسفور الميسر ونسبة الكربون الى النيتروجين (C/N ratio) ونسبة نسبة الكربون الى الفوسفور (C/P ratio) فى التربة أظهرتا إستجابة معنوية مرتفعة لجميع عوامل الدراسة خصوصا التركيزات المرتفعة منها مع البكتريا المذيبة للفوسفات. ولقد أظهرت معاملات

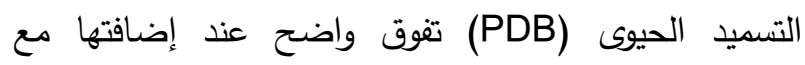
معاملات الأسمدة الفوسفاتية وحامض الهيوميك مجتمعة 